\title{
Grounding Emotion Appraisal in Autonomous Humanoids
}

\author{
by
}

\section{Kiril Kiryazov}

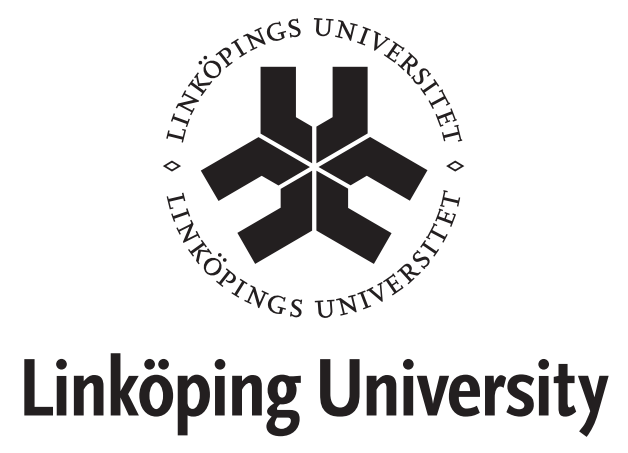
Department of Computer and Information Science
Linköping University
SE-581 83 Linköping, Sweden


This is a Swedish Licentiate's Thesis

Swedish postgraduate education leads to a Doctor's degree and/or a Licentiate's degree. A Doctor's degree comprises 240 ECTS credits (4 years of full-time studies). A Licentiate's degree comprises 120 ECTS credits.

Copyright (C) 2014 Kiril Kiryazov

ISBN 978-91-7519-336-6

ISSN 0280-7971

Printed by LiU-Tryck 2014

URL: http://urn.kb.se/resolve?urn=urn:nbn:se:liu:diva-105344 


\section{Abstract}

The work presented in this dissertation investigates the problem for resource management of autonomous robots. Acting under the constraint of limited resources is a necessity for every robot which should perform tasks independent of human control. Some of the most important variables and performance criteria for adaptive behavior under resource constraints are discussed. Concepts like autonomy, self-sufficiency, energy dynamics, work utility, effort of action, and optimal task selection are defined and analyzed as the emphasis is on the resource balance in interaction with a human. The primary resource for every robot is its energy. In addition to the regulation of its "energy homeostasis", a robot should perform its designer's tasks with the required level of efficiency. A service robot residing in a human centered environment should perform some social tasks like cleaning, helping elderly people or delivering goods. Maintaining a proper quality of work and, at the same time, not running out of energy represents a basic two-resource problem which was used as a test-bed scenario in the thesis. Safety is an important aspect of any human-robot interaction. Thus, a new three -resource problem (energy, work quality, safety) is presented and also used for the experimental investigations in the thesis.

The main contribution of the thesis is developing an affective cognitive architecture. The architecture uses top-down ethological models of action selection. The action selection mechanisms are nested into a model of human affect based on appraisal theory of emotion. The arousal component of the architecture is grounded into electrical energy processes in the robotic body and is modulating the effort of movement. The provided arousal mechanism has an important functional role for the adaptability of the robot in the proposed two- and three resource scenarios. These investigations are part of a more general goal of grounding high-level emotion substrates - Pleasure Arousal Dominance emotion space in homeostatic processes in humanoid robots. The development of the architecture took inspiration from several computation architectures of emotion in robotics, which are analyzed in the thesis.

Sustainability of the basic cycles of the essential variables of a robotic system is chosen as a basic performance measure for validating the emotion components of the architecture and the grounding process. Several experiments are performed with two humanoid robots - iCub and NAO showing the role of task selection mechanism and arousal component of the architecture for the robot's self-sufficiency and adaptability.

This research has been supported by the EU project ROBOT-DOC under G.A. 235065 from the 7th Framework Programme Marie Curie Action ITN (http://www.robotdoc.org). 


\section{Preface}

This thesis consists of six chapters which include an introduction and an overview of relevant research, and the following three articles:

- $\quad$ Paper I: Kiryazov, K., Lowe, R., Becker-Asano, C., \& Ziemke, T. (2011). Modelling Embodied Appraisal in Humanoids: Grounding PAD space for Augmented Autonomy. In Proceedings of the Workshop on Standards in Emotion Modeling

- Paper II: Kiryazov, K., Lowe, R., Becker-Asano, C., \& Randazzo, M. (2013). The Role of Arousal in Two-Resource Problem Tasks for Humanoid Service Robots. In proceeding of: IEEE 22th Symposium of Human and Robot Interactive Communication, Gyeongju, Korea

- Paper III: Kiryazov, K.\& Lowe, R. (2013) The role of arousal in embodying the cueXdeficit model in multi-resource human-robot interaction. In proceeding of: 12 th European Conference on Artificial Life, Taormina, Italy

\section{Acknowledgements}

First of all I want to express my big gratitude to Dr. Robert Lowe. He did the main supervision of this thesis and he was coauthor of all of the included papers. It becomes hard nowadays to find such a person like him with pure idealistic attitude to science. One of the best things of making this thesis is the possibility to work with him. He was very patient to all my delays and mistakes and despite of them always provided quick and professional feedback. Many of the original ideas of the thesis emerged after a discussion with him. Thank you, Rob!

After being so long abroad for first the time I have realized in a new way the importance of friendship. I am very grateful to my friends Emilian Lalev, Ivan Vankov and Alberto Montebelli for the fruitful discussions about topics of my research and about cognitive science and robotics at general. I thank them for making a proof reading of parts of this document. I want here to express my gratitude to my uncle Dr. Petko Kiryazov for the encouragement, support and fruitful discussions.

I wish to thank Professor Tom Ziemke for providing me with valuable feedback many times and being co-author of Paper I.

My $\mathrm{PhD}$ was a part of the Robot-Doc project (Marie Curie Initial Training Network ). It was amazing experience to be a part of a team of highly intelligent and creative people dedicated to science. I have the possibility to travel a lot and participate in many interesting training events and conferences. It was like a child 's dream come true to have the opportunity to meet top-scientists and work with cutting edge technologies such as the best humanoid robots iCub, NAO and ASIMO. I would like to express my big gratitude to Professor Angelo Cangelosi and Dr. Elena Dell'Aquila for their professional guidance and parental attitude to me and other $\mathrm{PhD}$ students, which participated in the project. Many thanks to all other fellows of the project, most of them become my friends. 
During my studies I have the possibility to visit few times the Italian Institute of Technology in Genoa, where the real iCub robot was created. I was very pleased from the welcoming, friendly and helping attitude of all the "hackers" in the institute. I would like to thank Professor Giorgio Metta for being my external supervisor and giving me freedom of accessing the iCub laboratory facilities . Also, I would like to thank Dr. Marco Randazzo from IIT for giving me advice about the energy management of the iCub and being coauthor of Paper II.

I wish to thank Dr. Christian Becker Asano who did part of my supervision. He came to visit us in the University of Skövde where we had some very fruitful discussions. It was inspiring to work with him - such an organized, sharp minded person. He is a co-author of Paper I and Paper II and gave me a lot of times very useful feedback.

I also would like to acknowledge Gauss Lee, Dr. Erik Billing, Dr. Boris Duran, Dr. Serge Thill and all other colleagues from University of Skövde for being such great teammates.

I am very grateful to Dr. Petru Eles, for his understanding and help when I was in a difficult situation. I also would like to thank Anne Moe, for all her efforts and patience with the administration of my $\mathrm{PhD}$ studies.

I want to express my gratitude to Professor Mariam Kamkar for being the official supervisor of this thesis.

Finally, I thank my parents, my sister and all my other friends.

Kiril Kiryazov

February 2014

Göteborg, Sweden 


\section{Table of Contents}

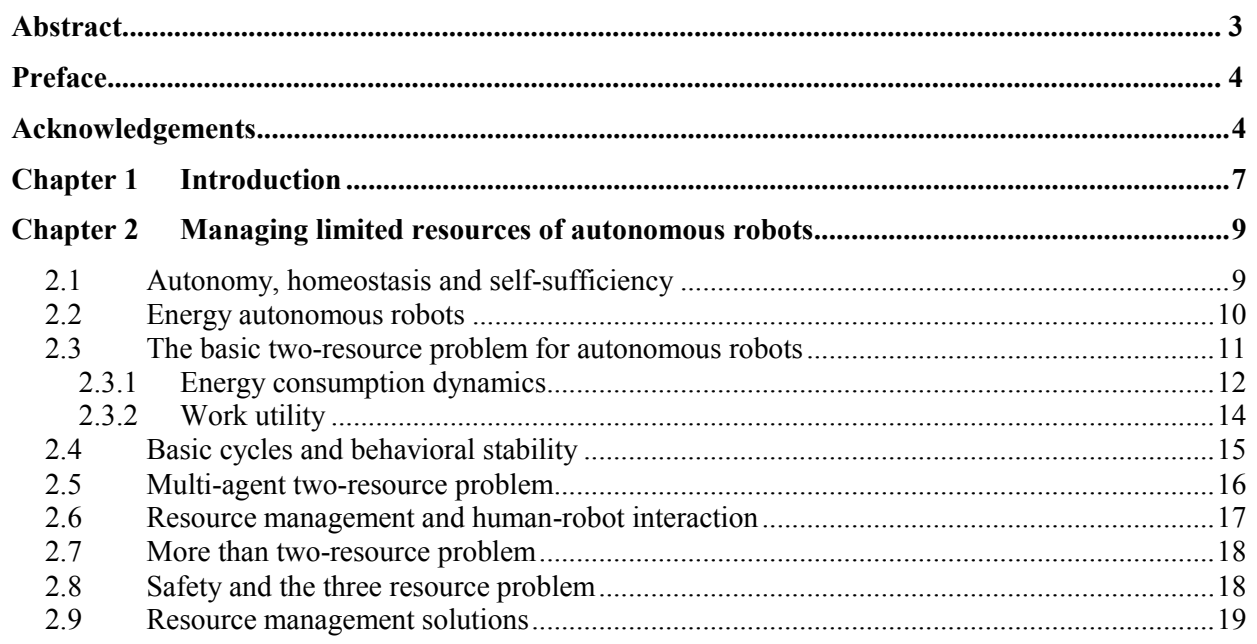

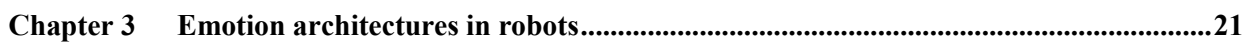

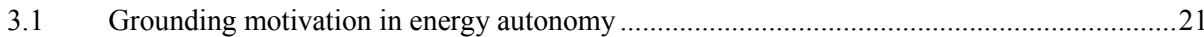

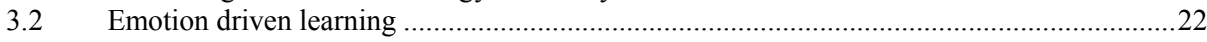

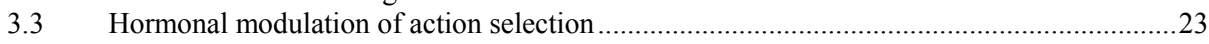

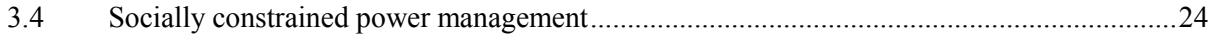

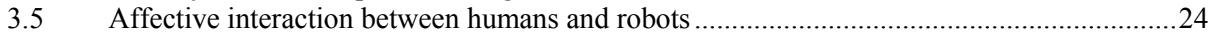

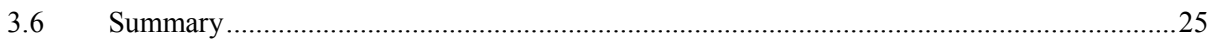

Chapter 4 Grounding of top-down models of emotions in homeostatic processes........................26

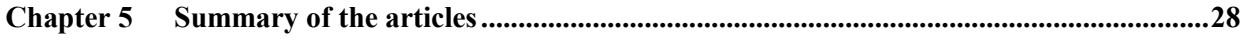

Chapter 6 Conclusion .......................................................................................................................................30

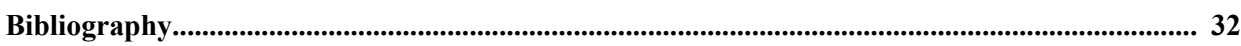




\section{Chapter 1}

\section{Introduction}

In recent decades research about emotional robots has grown in popularity in different areas of cognitive robotics (Cañamero, 2005). On the one hand, emotion is an important part of humans and animals, so robots, as modeling tools, should also incorporate emotion mechanisms. On the other hand, emotions have important adaptive roles in biological systems, for example: enabling top-down attention, providing reinforcement to the learning process, boosting relevant memory retrieval, triggering fast behavioral responses in urgent situations etc. (Breazeal \& Brooks, 2004; S. C. Gadanho \& Custódio, 2002), which could be useful for robots as well. From a functional point of view one of the main roles of animal's emotions is to provide adaptive goal selection mechanisms under different resource constraints (Breazeal \& Brooks, 2004; D. Cañamero, 1998). Animals have to survive in complex hazardous environments under the constraints of limited resources like food, water, heat etc. Evolution has provided solutions to these high-dimensional problems with non-trivial complexity. These problems sometimes are similar to the ones - which autonomous robots face while dealing with complex tasks in unpredictable environments. Robots also have to act under the constraints of different resources such as energy and workload. Service robots should work in a human habitable environment and cooperate with humans. One of the main challenges of such robots is to achieve their tasks related to human satisfaction with high enough performance under the constraints arising from various resources. A basic resource constraint is electrical energy supply. The robot market has grown continuously in the last few years and so does the cost of the energy used by the robots. Thus the efficient management of electrical energy becomes a more and more important issue for robotics researchers. Moreover, the charging process takes a big part of the robot's lifetime so it should be done efficiently in the most suitable time related to robots' work and their owners behavior (Deshmukh, Vargas, Aylett, \& Brown, 2010). In addition to determining the right time of switching between charging and working behavior, it is also a challenge to adopt the proper tradeoff between mechanical effort and energy efficiency. Safety is an important aspect in human-robot interaction, which needs to be taken more seriously into account as the service robotics market grows (Mandel, Huebner, Vierhuff, \& Christian, 2005). Another crucial factor for resource management of robots is the fast and efficient interaction with humans. Emotion-expression is considered as a fast communication channel (Bar-On \& Parker, 2000) which should be exploited by robots interacting with people (Breazeal \& Brooks, 2004). The emotion state of the robot expressed in a believable way could induce similar states in a human (Hatfield, Cacioppo, \& Rapson, 1994). Recognizing human emotions can also allow the robot to adapt its behavior regarding human emotion - useful heuristics for anticipating important events (Rani, Sarkar, Smith, \& Kirby, 2004). The papers supporting this thesis present a cognitive architecture at different stages of development for managing limited resources for robots in 
human inhabited environments. The presented architecture uses some bio-inspired task selection mechanisms, which are based on abstract ethological models (Sibly, 1975). The architecture treats physical constraints of the environment, social constraints and designer requirements in the same homeostasis regulation framework. In order to increase the efficiency of the animal strategies and make them more applicable to the service robotic world, where a robot should cooperate with humans, other bio-inspired mechanisms are used based on the appraisal theory of emotion. (Scherer, 1984).

The appraisal theory of emotion is widely used in cognitive robotics research (Lowe, Herrera, Morse, \& Ziemke, 2007). The work in this thesis pays extra attention to the arousal component of the emotion architecture, its generation through appraisal processes and its role in modulating the behavior of robots. Arousal is an important phenomenon which is a central part of almost every theory of emotions. The state of arousal corresponds to some neural and psychological changes induced in an affective way, which are supposed to have an adaptive role for coping with the emotional event. One of the main roles of arousal is to prepare the body for coping with the emotional event (Gadanho \& Hallam, 2002). Maintaining a proper level of arousal is tightly coupled to the homeostatic balance of the living organisms and is of crucial importance for optimal performance in daily tasks. (Silver \& Lesauter, 2008).

The minimalistic nature of the proposed architecture allows one to focus on the role of the coupling of the robot and the environment - its situatedness, embodiment and the emergent characteristic of the behavior of the robot. Moreover, it also makes the architecture computationally efficient, which is an important factor for the energy thrift. The architecture has top-down components which support representing and expressing high- level affective states. These states are grounded in bottom-up processes in the body of the robot in order to comply with recent research studies about emotion as hierarchically nested in different levels, where at the bottom is the metabolic process (Damasio, 2012).

Several experiments with humanoid robots were conducted in order to explicate the role of the affective components of the architecture in resolving the challenge of having to act efficiently under resource constraints whilst interacting with humans. More specifically, experiments with two humanoid robots- NAO and $\mathrm{iCub}$ revealed the role of the arousal component of the architecture in the above-mentioned problems.

The next section (2) begins with definitions of some of the basic concepts exploited in the thesis like "resource" and "autonomy". An overview of the main aspects of the problem of resource management for autonomous robots is provided. Special attention is given to resource managing whilst interacting with a human. A short summary of the major engineering approaches to handling the problems of resource management is provided. Section 3 gives an overview of the state of the art of robotic emotion architectures. A critical review of the most influential implementations is presented. Finally, a proposal for a new architecture for resource management is put forward. Section 4 is a short resume of the ideas for the grounding of top-down emotion components in the bodily processes of robots. Section 5 is a summary of the papers included in the thesis - the architecture developed, the experiments conducted and their results. Section 6 is an overview of the main contribution of this thesis. It also contains conclusive remarks and directions of future research towards a full $\mathrm{PhD}$ thesis completion. 


\section{Chapter 2 Managing limited resources of autonomous robots}

\subsection{Autonomy, homeostasis and self-sufficiency}

In order to define the most important problems in the area of resource management, first of all the basic concepts like "resource" and "autonomy" and related concepts should be specified.

A robot interacting with humans and not controlled remotely should have a high degree of autonomy as it will face a challenge to produce efficient actions (in alliance with its designer requirements) in an unpredictable and dynamic environment. Autonomy is a concept which is hard to be defined succinctly in a general framework. However one possible way to define it is an independence of outside control (McFarland, 2008). Such a definition suggests to predefine the boundaries of the agent for which autonomy is concerned. In the robotic case, that usually is the robot's controller or body (including controller). However, in some particular cases these boundaries can be moved further away and include the surrounding environment, for example the achievement of a certain task emerges from the coordination of swarms of robots (Ducatelle, Di Caro, Pinciroli, \& Gambardella, 2011).

McFarland has defined three different types of autonomy: energy, motivational and mental (McFarland, 2008) corresponding to the following three different levels of independence:

- From an energy source

- From the choice of particular set of actions for performing a goal

- From the choice how a certain goal is achieved

The first level corresponds to "energy autonomy". According to (Wawerla, 2010) "energy autonomy" should be distinguished from self-sufficiency. In his thesis Wawerla emphasizes the difference between the two concepts by giving the following definition of self-sufficiency

"self-sufficient agent, we mean an agent that satisfies its demand for all essential resources at every moment in time, over an extended period of time, in a given environment"(Wawerla, 2010)

Thus one arrives at the necessity for a definition of "resource". In the same work it is stated that:

"Every agent can be described by a set of hidden or observable state variables that defines its situation in the world ... Such state variables can be blood oxygen, body fat, money etc.. Within this thesis, we define resources as items provided by the environment or other agents that satisfy a need for at least one of the state variables." (Wawerla, 2010)

These important state variables will be referred to the thesis as "essential variables" in a way similar to (Lowe et al., 2010; McFarland \& Spier, 1997). The definition of a resource of Wawerla makes one background assumption which is important to be clarified. It supposes having some knowledge about the interaction between environment and body 
which allows to establish the pairing between certain actions related to a physical object in the environment and the change of certain essential variables of the robot. Generally, in order that such a pairing is there, it will require knowledge about the environment-body interaction. Usually authors, as in the current thesis, provide an ad-hoc solution for these problems by having in advance the pairing between certain essential variables and a representation of the corresponding object of the environment already predesigned. But it is important to be aware of that process which in the ideal case should emerge from the interaction between the robot and the environment.

The definition for a resource presented above is quite broad, including "intuitive" resources like an energy source (fuel) and some more "abstract" resources like work activity for example. The "items provided in the environment" do not necessarily need to take different locations in space as in most of the examples in (Wawerla, 2010) and similar research but it could happen that they are at the same space location while their gathering requires a different behavior. For example in (Radice \& McInnes, 2003) a space satellite should balance trade-off between the resources temperature and energy, which is maintained by switching on and off a heater which increases the temperature but decreases the battery level. Such a broader framework allows handling resources related to another important essential variable for every physical object like its integrity.

In the same work of Wawerla - two types of resources "viable" and "dispensable" are specified concerning whether the lack of the resource is causing the "death" of the agent or it is just not "desirable" (Wawerla \& Vaughan, 2008). The vital resources are easy to be defined however it is not clear what does desirable mean if it is not related to the agent's survival. For the animal desirable could be "evolutionary fit". However, the question what is a desirable resource for an artificial agent remains. McFarland in (McFarland \& Spier, 1997) provides an interesting analogy between the evolutionary pressure in animals and the designer's requirement for the robots:

" possible ultimate fitness function for autonomous agents may be based on satisfying the owner as opposed to simply surviving"

Such a framework where balancing the designer requirements is made analogical to the maintaining process of the internal agent's homeostasis is useful because it provides minimalistic solutions to the complex challenges for the autonomous robots - to remain viable from one side and from another side to fulfill the designer requirements. This framework takes inspiration from the basic mechanisms of homeostasis and bioregulation which exist in all living systems. It aligns with the cybernetics tradition and the notion of ultra-stable system developed in (Ashby, 1960). Ashby defines ultrastability as the ability of an agent to find a stable state for its essential variables when disrupting changes in the environment occur. In the implementation of his ultrastable system inspired by biological notion of homeostasis Ashby used several feedback loops. In one loop, the organism "directly" interacts with the environment via sensorimotor feedback. Through another loop, a random behavior is generated induced by the deviation of the level of the essential variables from some set point. The agent's behavior is adjusting the essential variables in a trial and error manner until equilibrium between the agent and the environment is achieved. Sensorimotor activity by the agent that leads to deviation from the ideal essential variable range may be considered analogous to pain in animals.

\subsection{Energy autonomous robots}

A physical robot or an animal will have absolutely no role in the world if it does not perform some actions. An action in the physical world requires some sort of mechanical 
movement. Any movement requires energy. Thus energy level is the most important essential variable for every living organism or robot (Wawerla \& Vaughan, 2009). Every energy autonomous robot should be able to gather and store energy and use it to perform desired actions. The energy storage/ consumption parameters (like storage limits) and internal dynamics are of crucial importance for the resource managing process. In the following section the existing power management systems and some of the basic properties of the energy system which are important for the energy autonomy are summarized.

In McFarland's study of robotic autonomy - (McFarland, 2008), "energy autonomy" is suggested as a basic requirement for the autonomy of robots. Robots which are connected to a power grid and cannot work unless connected are dependent on that particular energy source and as proposed by McFarland they are not energy autonomous. Jens Waverla (2010) points out that self-sufficient is often replaced by energy autonomous probably because the energy is the most-studied resource in the research of resource management.

A robot's energy is not only spent for performing movements. The robot's processor also needs power correlated with the intensity of the performed computation. An experimental study shows that a Pioneer DX robot consumes 33-65\% of its energy for powering its CPU (Deshmukh et al., 2010). However in the current thesis the research is focused on the relation between the movement properties and energy dynamics. Humanoid robots should consume much more energy for moving in space than a wheeled robot as Pioneer DX. For example just for a standing still posture a humanoid should empower its actuators as opposed to a wheeled robot which could just power-off and generally consumes less energy when it moves. Thus a proper power balanced movement for a humanoid robot should crucially relate to the overall energy expenditure.

\subsection{The basic two-resource problem for autonomous robots}

In the study of (McFarland \& Spier, 1997), it is suggested that the basic two-resources which an autonomous robot should handle are energy and work activity. In (Lowe \& Kiryazov, 2014) it is said:

"Generically, a two-resource problem consists of the need for the robot to cycle its behavior between two drive satisfying actions-relating to two resources. These resources may involve some notion of 'work', on the one hand, and some more or less complex form of 'refuelling', on the other hand."

Energy resources have natural dynamics depending on the specific energy storage system of the robot. In the most trivial case there is a fixed charger and for gathering energy the robot should find its location and move itself to it. Other types of robots like solar panel powered ones or Microbial Fuel Cell robot (Kelly, Holland, Scull, \& McFarland, 1999) need more complex systems for localizing the resource in the environment.

The "work" resource is more abstract and it is dependent on the designer's requirements as mentioned in the previous section. For example a cleaning robot should complete cleaning of its designated area at certain times in order to say that it fulfills its designer requirements - so in a more abstract sense - 'stays viable'.

The main questions which are important for solving such kinds of two-resource problems are:

- What is the time to switch from refueling to working and vice versa (Wawerla \& Vaughan, 2008)?

- Can we find the appropriate action set for the activities of gathering the resources (work and fuel)? For example can we find the path between the work and energy 
station (Parker \& Zbeda, 2007) or perform charging and docking (Deshmukh et al., 2010)?

- What is the most efficient way (corresponding to the two-resources expenditure) to perform each movement - in terms of speed, joint stiffness etc.?

This thesis mainly elaborates on the problems in the last topic in the list, which have not been exploited enough in the state of the art of resource management. A basic property of a certain movement which a robot performs is its speed. Higher speed leads to faster completion of the performing behavior thus a faster achievement of the designer requirements and gathering more of the work resource. On the other side, speed of the movement correlates with the homeostasis of energy. Moreover, higher speed usually provides more of a safety hazard. Safety in movement is an important designer requirement when the robot is required to interact with a human.

\subsubsection{Energy consumption dynamics}

Animals need to process energy in order to survive. Energy resource gathering and storage concern all the important life processes like movement, reproduction, growth, work. Mammals have a complex metabolic system in order to gather, store and use energy for their actions. Usually they are heterotrophs - use organic materials as a source of energy which are obtained by ingestion of other organisms (Klappenbach, 2013).

Robots have much simpler "metabolism" based on electric energy storage of some kind. In the table below the main energy maintaining systems available in research of autonomous robots are summarized.

Table 1 Types of "robotic metabolism"

\begin{tabular}{|l|l|l|}
\hline Type of energy system & Example robotics system & Resource in the environment \\
\hline Regular electric batteries & iCub (Sandini, Metta, \& Vernon, 2007) & Electric charger \\
\hline Solar energy system & $\begin{array}{l}\text { Mars rover Opportunity (Edmondson et al., } \\
\text { 2007) }\end{array}$ & Sun-light \\
\hline Microbial fuel cell & $\begin{array}{l}\text { Ecobot (Melhuish, Ieropoulos, Greenman, } \\
\text { \& Horsfield, 2006) }\end{array}$ & Organic matter, water \\
\hline Bio-gas fuel convertor & EATR (Wikipedia, 2013) & Biomass or gas \\
\hline Ocean thermal energy & SOLO-TREC (Buis, 2010) in & $\begin{array}{l}\text { Differences } \\
\text { temperature }\end{array}$ \\
\hline Ocean wave-energy & $\begin{array}{l}\text { Liquid robotics (Smith, Das, Hine, } \\
\text { Anderson, \& Sukhatme, 2011) }\end{array}$ & $\begin{array}{l}\text { Mechanical energy from ocean } \\
\text { waves }\end{array}$ \\
\hline
\end{tabular}

From the above table, it could be concluded that it is easier to provide an energy system for the robot inhabitating the ocean. Maybe that is one of the reasons that life has originated in water - it is easier to have a metabolic system there.

A solar powered robot needs to find an appropriate place where there is enough sun to charge the robot's batteries. Even when the sun light is not occluded all the time, it still makes sense to track the sun moving across the sky to optimize energy gathering (Wettergreen et al., 2005).

Organic matter and water usually are easily accessible in places where humans reside. For that reason a MFC robot (although its current implementations are quite limited in abilities) could be considered as having the potential for the "highest" energy autonomy 
from the list above in a human habitable environment. Of crucial importance for its energy systems dynamics is the charge/ recharge rate of its capacitor in relation to the availability of the fuel matter and water. An MFC powered robot will require both fuel and water to be self-sufficient through maintaining a viable charge /recharge rate of its capacitor. In this case a resource problem for maintaining its electrical energy could turn into a non-trivial two-resource problem as there are environments where both resources are depletable and have different locations (Lowe et al., 2010).

The main properties of an energy system corresponding to resource management problem are (Michaud \& Audet, 2001):

- Storage capacity (upper and lower limit)

- Rate of energy gain when charging

- Rate of energy loss when performing different actions

If all the resources vital for the robot are located at different places, the robot should move between them in order to manage their balance. In the case of no obstacles the main decision which the robot should take while it is approaching a resource is the movement speed. The functional relation between the movement speed and the electrical energy consumption per certain distance can basically have two profiles the adoption of which depends on the position of the optimal speed for the lowest energy consumption in the space of all possible speeds (Figure 1).
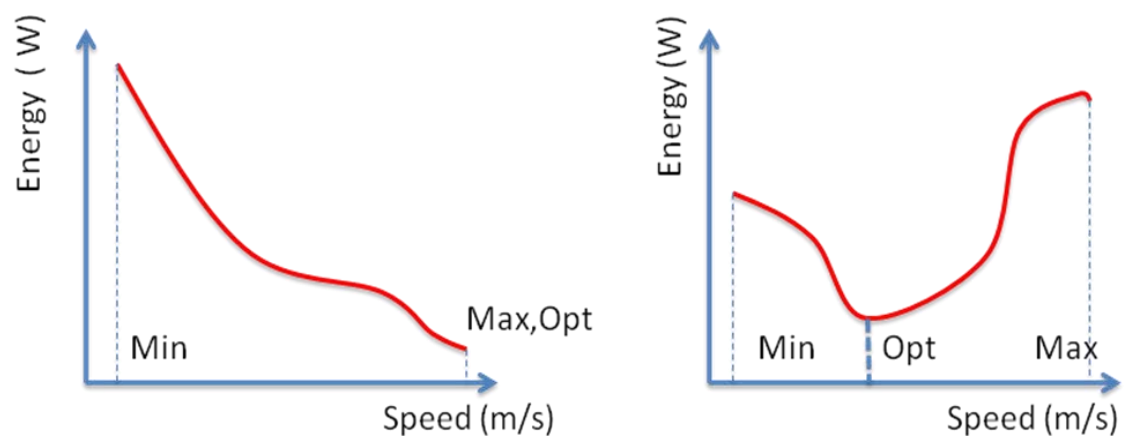

Figure 1. The basic speed/energy consumption profiles: (A) energy optimal is the fastest movement (left). (B) Energy optimal is not the fastest movement (right) Min is the lowest possible speed of movement. Max is the highest possible speed. Opt is the optimal speed for lowest energy consumption.

Analogical distinction can be found in a study regarding horses' oxygen consumption in (Hoyt \& Taylor, 1981). Different patterns of horses' gaits obtain an inverted u-shape relation between the running speed and oxygen consumption ("B" profile). Only the data from the fastest gait- gallop has the "A"-energy case. Although this data could be not be complete because of ethical concerns - the horses are not forced to run at a too high speed.

Industrial robot arms (Kolíbal \& Smetanová, 2010) have the "B" energy consumption profile too. It is obvious that even if a robot has the " $\mathrm{B}$ " profile it could still be reasonable that only certain speed limits are exploited for safety reasons so practically it could be put in the "A" category (if the Max speed is switched to a value lower than the Opt speed). Generally, such kind of categorization should include a third profile, in which the lowest possible speed is the optimal one. Such a profile however is unrealistic for humanoid robots which all the time should compensate for gravity and making very slow movements is energy inefficient. 
In the first case (A) in order to gain benefits from the resources of both kinds (work, energy), the choice of an optimal speed is trivial, the robot should simply move at the highest possible speed. In the other case the choice of speed is a challenging optimization problem. So in the basic two-resource problem, a crucial factor is to have an adaptive strategy depending of the current available type of energy consumption dynamics, which chooses the proper speed of movement. Even in the A-case however the resource problem is not trivial when safety is concerned as it could be seen below.

\subsubsection{Work utility}

Evaluating work performance is generally a high level task that requires the robot's designer's decisions. In (McFarland \& Spier, 1997) three different classes of work utility functions were specified depending on how one evaluates different stages of the robot's behavior when it is not working i.e. it may be either neutral (0) or negative (-).

Table 2 Basic work utility types (adapted from (McFarland \& Spier, 1997), page 2)

\begin{tabular}{|l|l|l|l|}
\hline & Work & Find fuel & Refuel \\
\hline Utility type I & + & - & - \\
\hline Utility type II & + & $\mathbf{0}$ & - \\
\hline Utility type III & + & - & $\mathbf{0}$ \\
\hline
\end{tabular}

Maybe one could consider the above table as incomplete as it does not assign any utility to the obvious fourth behavior "going to work". Of course not all types of environments will allow the robot to start working immediately after refueling as working, similar to finding the charging place could require moving to a certain place first where work needs to be performed. For example in studies of two-resource problems (Wawerla \& Vaughan, 2008) and (Avila-García \& Cañamero, 2004) this aforementioned behavior is separately studied. In the robot ecosystem (McFarland \& Spier, 1997) robots should knock lamps in order to work but "go-to" work will obviously require energy and time to move to the lamps. However, the reasonable utility value in this "going to work" behavior could be the same as in the "going to fuel" behavior (neutral or negative).

Assigning negative utility to certain behaviors would prevent an unconstrained increasing of the work resource which is an implicit necessity if we need the resource to have a depleting dynamics suitable for the homeostatic framework described above. As we have seen before, maintaining homeostasis presupposes that all the resources could be depleted at a certain moment. On the other side, this would allow to obtain analogy to an animal and work can be also mapped to some of the animal's vital resources like food or mating. Of course, such a constraint is not obviously required from the designer's perspective of a general performance measure of the work of the robots. In the architecture developed in this thesis, an attempt is made to have a work utility function which succeeds in naturally representing a reasonable requirement for robot performance and from another side has such "depleting" continuous dynamics (see Paper II). This work utility has dynamics of the type I (from Table 2) which however is not provided ad-hoc (explicitly set an abstract value to the different robot behaviors.) but emerges from a natural evaluation of the performance of the robot and its interaction with the environment.

Work utility classification in Table 2 doesn't explicitly consider the time when the work is performed. In (Wawerla \& Vaughan, 2008) arguments are provided that timing of work is of crucial importance. As he states "work that the robot performs now is always more valuable than the same amount of work performed later". In that research for a two- 
resource problem he assigns a discount factor of work utility which is increasing with time. In the architecture provided in this thesis, there is no explicitly set discount factor. However, one could consider that discounting of the work emerges from the dynamics of the work utility and the robot- environment interaction.

\subsection{Basic cycles and behavioral stability}

An energy autonomous robot doesn't have an unlimited power supply, which means that its energy level will have cyclical dynamics over time modulated by the charging/discharging activities, naturally constrained with an upper and lower limit determined from the energy storage system properties. Generally speaking, because of the physical constraints for any material objects, the dynamics of any physical resource will have upper and lower limits. In the study by Wawerla (2010), it is pointed out that removing the upper limits in a robot inhabiting a virtual world could significantly simplify the problem of task selection. As mentioned in the previous section, work utility could also have similar properties if defined properly. A robot maintaining homeostasis by managing its resources will have a behavior with cyclical properties. As claimed in the study (Hallam \& Hayes, 1992) - "Cyclic behavior occurs automatically in robots with rechargeable batteries.".

If all the resources which a robot should handle have limited and continuous properties, trajectory (of the essential variable) of such a robot will be cyclical in the space of the essential variables corresponding to the resources. This trajectory provides an intuitive way of selecting a goal for the robot's controller - the robot should not go into irrecoverable deficit in any of the state variables (McFarland \& Bösser, 1993). In the case the trajectory goes too close to the lethal boundaries (planes defined from the extreme levels of essential variables, which leads to the death of the robot or to an unacceptable behavior from the designer's point of view) that is an indicator for unstable behavior and vice versa. McFarland proposed a basic measure of behavioral stability - the robot should produce sustainable behavioral cycles for a sufficient amount of time. Reasonable is the question of how long "sustainable" should be. McFarland doesn't give an answer, it is obvious that this relates to the complexity of the environment where the two- resource problem should be solved. If the complexity of the environment is hard to assess in advance, it also makes it more complicated to evaluate the required number of cycles for estimating if a certain behavior is stable or not. As seen in the previous section McFarland identified the following three main parts of the basic cycle - "work", "search for fuel" and "refuel". If we plot the dynamics of the state space of the two resources one basic cycle will have the following profile (Figure 2 - left). 

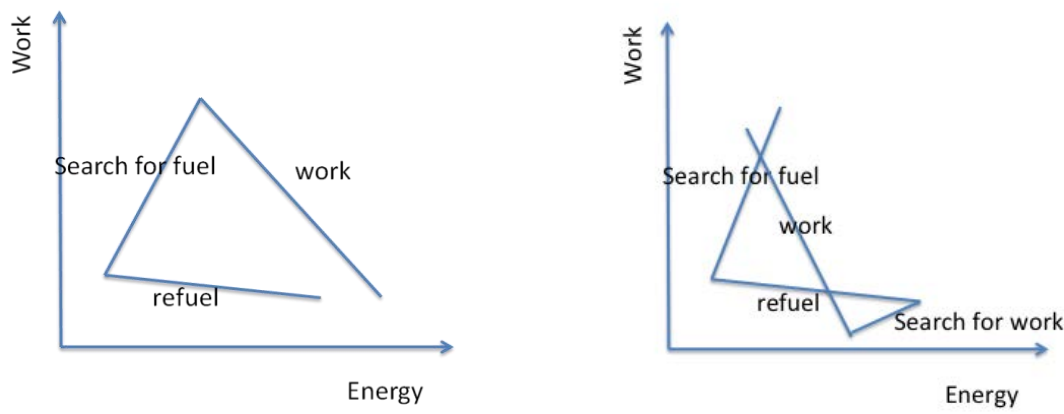

Figure 2. (left) Stages of basic cycles of energy autonomous robots. Adapted from (McFarland \& Spier, 1997); (right) Extended version of the basic cycles for energy autonomous robots

If we include the forth obvious behavior - "going to work" mentioned in the previous section the basic cycles takes the form in Figure 2 (right).

In his "Work-Refuel" model (Wawerla, 2010) identify the same four stages (two stages "work", "refuel" and two for the transitions between them). Analogical four different stages with the similar dynamical relations are observed in the work by Avila-García and Cañamero (2004) regarding the two-resource problem where however the resources are heat and food. In the same paper two different types of behaviors are defined corresponding to the four stages - two consumatory and two appetitive. Consumatory behaviors are related to gathering the resources, appetitive - approaching them.

In a lot of scenarios like the ones used in this thesis, it could happen that two types of behavior are naturally combined and it is reasonable only appetitive behaviors should be included in the task selection mechanism. For example a cleaning robot - the robot recharging could start almost immediately after it has arrived at the target location if the charging station and robot have the correct properties.

Monitoring the state space dynamics could be useful to find important properties of the behavior of the robot like for example opportunism and over-opportunism (which are beneficial or harmful for the robot viability and efficiency) (Avila-García \& Cañamero, 2004) and are important criteria for the robot's motivational autonomy (McFarland, 2008).

\subsection{Multi-agent two-resource problem}

When an animal should maintain behavior stability under resource constraints there are usually competitors - other animals which desire to consume the same resource. That significantly increases the complexity of the problem as the animal should additionally choose if it should avoid a certain resource because it is already "occupied" by another animal or decide to fight and push the competitor off the resource. In the study (AvilaGarcía \& Cañamero, 2004) two-resource competitive robot experiments are showing the extra challenges which occurs when there is a competition compared to a non-competitive scenario.

However, in most of the practical robotic scenarios, such type of "aggressive" competition is usually not so likely to happen. Few exceptions are related to different robotic games which are made for a performance benchmark (Michel \& Rohrer, 2008) for different intelligent architectures. Most of the practical examples would consider cooperation between the robots instead of competition. However even when cooperative, 
having another agent in the environment, the complexity of the problem of resource management increases because the robot should additionally (Novitzky et al., 2012):

- recognize the other agent- find its location in the environment and its current action

- recognize the status and intention of the robot (what is its current resource deficit and the chosen action)

- express its intention in a meaningful way to the other agent

- perform an action in a way considering its effect on the other agent

It could be argued that the first three points could be easily solved in the case when all the agents are robots as we could have a centralized controller - one architecture to control all the robots. That is however not entirely true because wireless communication could be a main source of energy consumption and make the robot more expensive and complex (Hoff, 2011). It could be more efficient if every robot had the same local resource management strategies. On the other side, any centralized approach has its drawbacks as for example fault intolerance. Moreover, all these three problems are not trivial in the case when the other agent is a human.

Having multiple robots which should efficiently manage co-operation recharging activities provides an interesting social solution to the resource management problem. For example (Zebrowsk \& Vaughan, 2005) a robotic simulation was performed where one specialized robot - tanker moves in the environments and searches for robots which need to be recharged. Some authors develop robot teams where the robots could exchange power between each other by physically exchanging batteries or just transfer a certain amount of their battery power (Ngo \& Schioler, 2006).

\subsection{Resource management and human-robot interaction}

When an autonomous robot is situated in a human habitable environment and the task is supposed to be performed in cooperation with humans, the challenges described for the multi-agent resource management have some specific properties. The robot should detect the human's body position at any time (in order to avoid collisions for example). It should meaningfully interpret the social signals (verbal and nonverbal) and act accordingly (Bicho, Louro, \& Erlhagen, 2010). For that reason the robot should first be able to recognize the human internal state (e.g. the human is tired and the robot should slow down and/or spend more energy on anticipating possible failures if the human is anxious - an eventual signal for anticipated danger (Rani et al., 2004). On the other side, the robot should express its internal state (for example express anxiety if it is not able to respond to high work deficit so the human is aware that the robot probably needs help). Humans are able to process and exchange information via different social signals. One very time efficient way to exchange information is by expressing/ interpreting emotion state (Bar-On \& Parker, 2000; Breazeal \& Brooks, 2004)

One crucial aspect in any human-robot interaction is safety (Kuli , 2006). To maintain safety as it was mentioned above the robot should sometimes "sacrifice" fast task accomplishment and correspondingly decrease the level of the work resource. Acting in a safe manner could be considered as another "abstract" resource (with a separate essential variable corresponding to the amount of the safety hazard). Thus the basic challenge for a robot interacting with a human could be a three - resource (energy, work, safety) problem. 


\subsection{More than two-resource problem}

McFarland has suggested that the two-resource problem is a basic problem in resource management and the one-resource problem is trivial. In (Wawerla, 2010) however nontrivial variants of one resource problems are presented. It is pointed out that even if there is only one essential resource in the environment for the robot, there could be several different behaviors to gather it (for example there are two chargers and the robot should choose which one is more suitable in a particular moment) so it makes the resources problem again non-trivial. Actually even the two-resource problem scenarios developed in (McFarland \& Spier, 1997) could be considered as one-resource where the only resource is energy - and "working" (knocking on lamps) could be seen again as high order charging behavior because this is the only way that the robot can "buy" energy with its work points later .

It is interesting to show how the resource management challenges scale up when the essential resources are more than two. In (Spier \& McFarland, 1997) it is claimed that adding a third resource doesn't increase considerably the complexity of the problem as task selection mechanisms could consider at any time the choice between one of the resources and a bundle of the rest. However as seen in previous sections, not only is the resource selection important, but the specific properties of the robot's behavior used for the resource gathering could influence the energy consumption dynamics and therefore substantially influence the resource management, which could make three- resource problems interesting to study as well.

In addition to energy, another obvious resource which an autonomous robot should handle is internal heat (too much power could lead to better performance but at the same time could lead to overheating which could be damaging for the robot (Ma, 1999). In (Radice \& McInnes, 2003) in addition to the basic two-resources (energy and work) the robot should balance its internal heat. Safety is a basic work performance requirement when the robot is interacting with a human and could be considered as a third resource as mentioned above.

\subsection{Safety and the three resource problem}

Safety is one of the major aspects of human-robot interaction (Kuli , 2006). The robot interacting with a human should always maintain some safety demands in addition to its basic performance requirements - its primary working task. In the proposed two -resource framework, safety could be considered as a part of the work utility (general designer requirements) and still one has to solve a two-resource problem. However, as it was considered before safety could be a separate third resource because it usually requires an opposite modulation of the movement effort compared to working. Higher speed and joint stiffness usually lead to faster and more accurate task achievement but increase the safety hazard. We can say that in a some abstract space safety and work are separate resources having different locations.

Speed of the robot is a major factor for calculating the eventual collision strength with humans (Kuli , 2006). Other factors of the more general concept of effort of movement like joint stiffness are also important for safety. Therefore effort and safety are tightly connected.

In order to exploit the role of the effort (and more specifically movement speed) to the so proposed three resource problem, one of the most important factors is the type of "energy metabolism" which the robot has. In Figure 3 with "+" resources which benefit 
from the same change of speed (acceleration / deceleration) are connected, and with "-“ the links between the resources, which require the opposite "speed behavior" are marked.

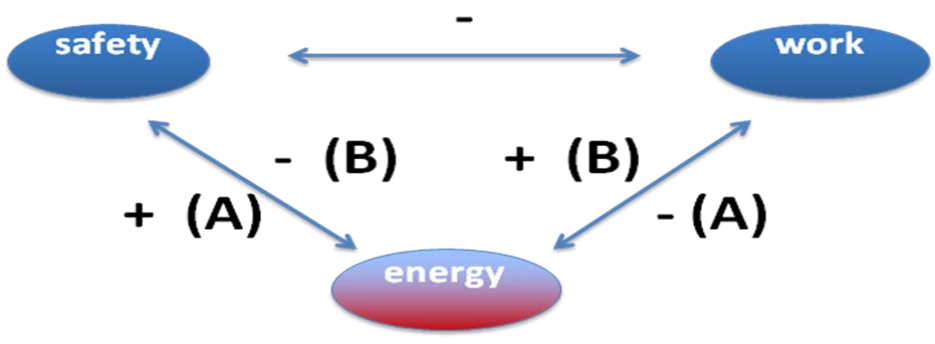

Figure 3. The role of movement speed for defining optimization tradeoffs for the three resource problem ( in both cases of energy metabolism - "A" and " $B$ ")

The change of the speed (effort) for "gathering" safety could be done in different ways. Usually when a safety hazard is detected an industrial robot completely stops. This solution is also used for gathering safety in Paper III. Another more flexible solution which could be suitable for "soft" robots is just to slow down or decrease joint stiffness when safety should "be gathered".

\subsection{Resource management solutions}

As it was shown, one of the basic problems for resource management is the appropriate action selection. The good old fashioned AI strategies of action selection are based mostly on some sort of planning algorithms. Planning usually supposes having a model of the environment (complete knowledge of how the actions of the robot reflect the change in the state of the world). If such a model is available, one can use planning strategies like $\mathrm{A}^{*}, \mathrm{D}^{*}$ (Johansson \& Balkenius, 2006; Wettergreen et al., 2005). The benefits from using such algorithms are obvious - there is usually a guaranteed optimal solution. Among the drawbacks, it also holds that the complete knowledge of the environment is very hard to obtain and even if it is available, it usually contains errors. So such approaches are not robust to noise and unpredicted events.

At the other extreme of planning algorithms there are reactive algorithms, which rely only on the current sensor data to take a specific action. The classical example is Braitenberg vehicles (Braitenberg, 1986). Reactive algorithms are computationally very simple and don't require models of the environments. But of course their behavior could be very limited as the robot doesn't keep track of past experience and doesn't have a representations of its goals - future desirable states. It is interesting whether a purely reactive architecture can solve a resource management problem as a resource deficit usually reflects some internal state of the robot. However, as mentioned before having internal states is not always necessary in order to provide some solution for the resource balance problem. For example in (McFarland \& Spier, 1997) it has been observed that a very simple purely reactive algorithm (using only external cues from the environment) for action selection gives very close performance to the "winner" - the cue-deficit strategy of action selection in most of the environments.

If the sensing of the resources like for example battery level is considered as external to the robot there are a few examples of such reactive architectures for two-resources problems (Jung, Nies, \& Sukhatme, 2002). The subsumption architecture of Brooks 
(Brooks, 1985) is a classical application of a reactive architecture tested in a real world problem in complex unpredictable environments (Toal, Flanagan, Jones, \& Strunz, 1996). There are a lot of attempts to combine the strengths of both previously shown extremes reactive and planning - trying to avoid their drawbacks and building hybrid systems (Arkin \& Mackenzie, 1994).

Another way to solve non-trivial tasks like resource balance is to use black box strategies as artificial evolution (Parker \& Zbeda, 2007). The advantages of evolutionary algorithms are obviously in the cases when they succeed to find suboptimal solutions in the absence of designer intervention. Among the drawbacks, there is the long time to finish, which generally requires experiments in a simulator rather than in the real world and of course there is no guarantee for finding a solution. Wawerla, (2010) considers artificial evolution as not the best solution for resource management for several reasons as for example once evolved and transferred to the real robot, the algorithm is not changing any more so that it makes it rigid to unpredicted changes of the environment.

In addition to "engineering" solutions like the one mentioned here, a big part of the state of the art exploits architectures taking inspiration from affective mechanisms in biological systems. 


\section{Chapter 3 Emotion architectures in robots}

Usually the reason to develop an emotion robotic architecture is two-fold: to provide an experimental demonstration of the principles of an emotion theory, or to exploit the functional role of emotion in animals and humans in order to develop emotion-inspired mechanism for improving the robot's behavior. In order to say that a robotic architecture is an emotion architecture it should be based on one or more emotion theories. Some of the most famous theories of emotion are:

- Behavioral theories (Watson \& Morgan, 1917)

- Somatic feeling theory (Cannon, 1927)

- Processing mode theory (Oatley \& Johnson-laird, 1987)

- Somatic theory (Damasio, 2003),

- Cognitive appraisal theory (Lazarus, 1994)

- Embodied appraisal theory (Prinz, 2006)

In order to differentiate the functional roles of the emotions inspired mechanism in achieving the robot's tasks one could use the following (Cañamero, 2005; Thill \& Lowe, 2012) :

- Homeostatic behavior under different resource constraints

- Plan evaluation and plan switching

- Saliency in perception

- Reinforcement (value - system)

- Interrupting ongoing behavior in case of unexpected change in the situation

- Managing social behavior and communications

Yet another way classifying the emotion robotic architectures is to differentiate the specific implementation methodologies which are used:

- $\quad$ Rule-based systems

- Reinforcement learning

- Neural networks

- Evolutionary algorithms

- Agent based solutions (society of mind)

Of course the categorization criteria mentioned above are not exclusive - there could be an architecture inspired by several emotion theories, implementing various functional roles of emotion and using multiple modeling methodologies. This is why in this thesis there is no focus on specific theories, functional roles or modelling techniques in order to describe the state of the art. Instead, a critical review of some existing emotion architectures.which have an implication to the developed emotion architecture in the thesis is provided.

\subsection{Grounding motivation in energy autonomy}

In (Lowe et al., 2010) a bottom-up architecture for providing a Microbial Fuel Cell (MFC powered wheeled robot with energy and motivational autonomy was presented. The 
architecture was tested in a two-resource problem scenario where the resources were food and water corresponding to the MFC mechanism's essential variables. The architecture doesn't explicitly encode any knowledge about the resources in the environment - the pairing between the related objects and the corresponding metabolic processes is in the robot's body (which was discussed in section 2). The bio-inspired architecture contains an active vision component connected to the MFC module via an adaptation of a gas-net network. This network is an artificial neural network, where some of the nodes (in this particular case connected to the essential variables) emit gas which continuously modulate the activity of the neighboring nodes. The architecture uses an evolutionary algorithm to tune its parameters in a way to allow the robots to solve the two resource problem. The evolutionary algorithm evolved not only the weights of the network but also its topology (number of nodes). The robot in this case can be considered to have energy and motivation autonomy (see section 2.1). The gas-net network represents some sort of bottom-up cuedeficit algorithm as it provides motivation for choosing the "correct" resource based on internal deficit and environmental cues. The gas-net component could be seen as means of grounding high-level cognitive states (active vision) into metabolism processes provided by the Microbial Fuel Cell dynamics. The results of the experiment reveal some interesting findings about the usefulness of grounding the motivational states in the robotic metabolism in order to increase the robot's adaptivity in the two-resource scenario. For example, that a higher metabolic constraint on the evolved solution could lead to better robot performance.

\subsection{Emotion driven learning}

In (Gadanho \& Custódio, 2002; Gadanho, 2003) a robot architecture is presented which finds proper coordination of several hand-coded behaviors in order to increase the viability of a robot in real world scenarios. A reinforcement learning subsystem is connected to a "goal" system which provides reinforcements to the learning process by managing a set of homeostatic variables (the essential variables for the robot). The "emotion add-on" (goal subsystem) is inspired by the Damasio hypothesis about emotion as a general homeostasis balance system. Similar to the work in the current thesis, the homeostasis variables have continuous dynamics based on the deficits of the different important resources, which correspond to a set of regulating behaviors. A combination of perceptual values and internal signals are used to compute the single emotion state which is similar to the appraisal process and emotion representation in the architecture provided in the thesis. The robot should not run out of energy while searching for chargers and should avoid obstacles. We could say that the architecture solves again a two-resource problem where one of the resources is the energy and the other is the robot's welfare. The second one corresponds to the body integrity mentioned in the previous section, which level is decreasing in the case of events which harm the robot like crashes into the obstacles. Using reinforcement learning, a robot's controller can adapt through its life time to the environment while searching for a solution to a problem. Reinforcement learning could be seen as a tradeoff between supervised learning algorithms where a designer should provide an error signal for every action of the robot and unsupervised learning when there isn't any error signal at all. In reinforcement learning, this signal is provided at specific states of the world. One of the biggest drawbacks of the reinforcement learning algorithms is that the definition of appropriate reward is not a trivial problem itself (similar to defining the fitness function in an evolutionary algorithm). However, multi-resource scenarios could provide a good framework for the reinforcement learning approach as the reward could be naturally defined and assigned to the states where the robot is consuming a resource and a 
punishment when it goes close to a lethal limit of some of its essential variables. Another challenge for reinforcement learning is when to trigger state transitions. In the presented architecture, the emotion component is used to trigger such transitions when the emotion intensity is surpassing a certain threshold. In these studies of Gadanho, it is empirically shown that the emotion "add-ons" to the reinforcement learning subsystem increases the adaptivity of the robot (according to several indicators like time to accomplish the learning process).

\subsection{Hormonal modulation of action selection}

In (Cañamero, 1997) a hormonal-like mechanism is used to modulate an ethologically inspired action selection architecture in order to improve the robot's viability when environmental challenges increase - having another robot competing for the same resources. The action selection mechanism is a variant of a cue-deficit model. The cuedeficit model is a top-down ethological model which takes inspiration from optimal foraging theory assuming that animals are tuned evolutionarily to solve optimally foraging problems maximizing energy intake per time. The model is computationally simple but at the same time it provides a solution to complex resource management tasks. The motivation for selecting a behavior for gathering a certain resource is based on two basic variables: cue and deficit, corresponding to the strength of the external stimuli from the perception of the resource and internal deficit of it (deviation of the values of the essential variables from its ideal range corresponding to the resource). In its original form the agent with a cue-deficit model of action selecting should not search for a resource if its cue is zero - it is not visible from the agent, regardless how high is its deficit. That is considered a significant drawback by the authors in this study who modify the cue-deficit rule adding more weight to the deficit so the agent still searches for it even it is not visible. Another modification of the cue-deficit strategy is that cue value is varied from the hormonal module providing some sort of saliency mechanism.

Cue - deficit strategies could be considered a particular implementation of a more general $d r k$ strategy of action selection (Spier \& McFarland, 1996). Instead of the simple cue representing the external signal from the environment of the resources detected by the agent-extra parameters providing information of the ease of gathering of the resource can be used - availability and accessibility, which basically represents the concentration of the resource in the environment and the speed of gathering when it is accessed. The $d r k$ model has been applied in energy autonomous robots who search and eat slugs in order to maintain their energy (Kelly et al., 1999).

In the work of Cañamero several useful for the resource management emergent properties of the robot's behavior were found like opportunism and persistence. It is empirically demonstrated that the hormonal modulation crucially improves the action selection mechanism in order to tackle the new challenges in the environment. In the presented architecture in the thesis is also used a cue-deficit strategy. An arousal mechanism similar to the hormonal one presented here modulates the action selection for handling extra environmental challenges such as urgent situations in interaction with humans. 


\subsection{Socially constrained power management}

If a robot has the ability of representing and expressing human-like emotions this could be very useful for service robots interacting with humans as it was shown in Section 2. Enabling robots to have the ability to express human-like emotions could lead to anthropomorphism. However it should be pointed out that a robot which is able to recognize or express emotions doesn't necessarily have emotions, i.e. the underlying mechanisms analogical to those found in humans. (Thill \& Lowe, 2012).

In (Deshmukh et al., 2010) a top down model of emotion based on appraisal theory is used for balancing a robot's energy needs and its social tasks. The top-down components of the model allows the robot to easily express explicitly its current state and plans to a human in an understandable way (i.e. verbally). The social demands are viewed as a constraint of the homeostatic behavior of the robot which is similar to the idea presented in this thesis- to treat the social and energy demands as equivalent. The architecture is implemented in a wheeled robot with a display of human facial expression in a social helper scenario. However there are no comparative results to show the role of the emotion components in resources balancing or experiments providing evidence that the robot could have long- term behavioral stability.

\subsection{Affective interaction between humans and robots}

Breazeal (Breazeal \& Brooks, 2004; Breazeal, 2004) presents an affective cognitive architecture implemented in a robotic head in a human-robot interaction scenario. The architecture takes inspiration from ethology that the basic motivational forces should be the "drives" which satisfy certain essential needs of the organism. Instead of having animal's drives related to hunger, thirst etc, the robotic architecture has analogous drives for social contacts, playing, boredom and fatigue. The drives subsystem is connected to another emotion component based on appraisal theory which modulates the emotion state in Pleasure Arousal Dominance space (PAD), An emotion state is a single point in 3 dimensions, which moves continuously driven from the appraisal process. Similarly, in the architecture developed in this thesis, the emotion dynamic component is used to modulate a single emotion's state in the PAD space from an appraisal module. The use of dimensional models, such as PAD, is reasonable for human-robot interaction scenarios as they reduce high dimensional space into discrete emotion categories which can be easily mapped to some believable emotion expressive behaviors. These expressive behaviors are signals to a human who can adapt its actions according to the robot's needs thus regulating the robot's homeostatic balance. In addition to reflecting expressive behavior (facial expression or body posture) this emotion's state biases the cognitive system in various ways by focusing attention, prioritizing goals, etc. The architecture is agent based, having specialized agents for drives, emotions, behaviors etc. Regardless of their specialization, the units are connected in a network seeding valenced activation and symbolic messages.

It is interesting to see how a single emotion architecture could combine ideas from a number of emotion theories but this approach can also turn out to be too eclectic and complex. The robot's behavior looks natural and believable and several experiments are performed to evaluate how engaging the robot is in the interaction with humans. However there are not experiments validating the role of the robot's emotion components in its long term sustainability. 


\subsection{Summary}

As we can see from the examples given above, most of the architectures which address subemotion levels and bottom-up mechanisms provide flexible biologically plausible solutions of the resource problem but it's hard to see how these architectures scale up to present human-like affective mechanisms. It is not clear how the bottom-up architectures are scalable to be implemented in more complex robots such as humanoids which have to interact with humans. Moreover, the top-down architectures don't provide appropriate criteria or experimental evidence for long term self sufficiency in the resource management tasks. In this thesis, an attempt is made to bring both approaches together by grounding topdown emotion models in the body processes of humanoid robots. 


\section{Chapter 4 Grounding of top-down models of emotions in homeostatic processes}

In order to provide a robot with a model of animal's affective mechanisms a proper analogy between an animal's and a robot's world should be made. For example, such an analogy could concern the resource management. Animals should deal with resources like food, water and mating, where the robot has to balance its electrical energy, work efficiency, and safety when a human is nearby. In (Wawerla \& Vaughan, 2008) is stated that animal and robot worlds are quite different because:

"The rational robot and its owner are interested in gaining maximum reward by working at the robot's task, and are indifferent to the lifespan of the robot. This is a key difference between the purpose of robots and animals."

However, as it was shown in the previous two sections, both worlds could be connected using an appropriate mapping . This mapping - based on structural correspondence - will be to a certain extent "disembodied", as it will connect systems with different body/environment properties. As a result of the mapping it is possible to transfer some affective mechanisms. In order to enrich these transferred mechanisms and in order to be able to exploit better the specific body/environmental properties, these affective mechanisms should be tightly coupled with the particular sensory/motor components of the robotic body. One way to provide such coupling is to ground the top-down models into specific properties of the robot's body (e.g. energy level dynamics).

Using top-down cognitive models in robots was found to be beneficial because it allows high-level cognitive mechanisms to be incorporated in the models. Such mechanisms could be useful for making a meaningful and efficient human-robot interaction. Such high-level mechanisms are quite hard to be generated via bottom-up algorithms like evolutionary algorithms.

"...emergence of higher level psychological/cognitive competences are not easily amenable to minimalist evolutionary robotics approach. After all, it took biological evolution several billion years to go from single eukaryotic cells, with all their surprising complexity, to multi-cellular organisms with nervous systems and neo-cortical processes." (Lowe \& Kiryazov, 2014).

From another side, it was shown that using ethological top-down models in resource management tasks provides simple, computationally cheap algorithms for behavioral switching.

Grounding of top-down models in bottom-up mechanisms provides a two-way dynamics which will decrease the designer's control and potentially give the robot more autonomy, which could lead to increasing efficiency in uncertain and non-deterministic environments (Lowe \& Kiryazov, 2014).

According to Damasio (2003) emotions are grounded according to a homeostasis nesting principle . At the bottom level are metabolic processes, pain -pleasure behaviors etc. At the top-most level are high-level emotions and feelings (Damasio, 2003). One way of following 
Damasio's perspective is to ground affective states of top-down emotion models (top-level) in sensory-motor capabilities (bottom-up level).

Appraisal theory is dominant among emotion theories. Generally, an appraisal process consists of an heuristic evaluation, which processes the state of the world according to some internal needs or goals of the organism. According to cognitive appraisal theories, the detected changes in the inner or outer conditions are judged according to cognitive states as intentions, beliefs and generate some internal "emotional" state. As a response, the emotion system changes the behavior disposition or internal state and in this way adapts to the appraised situation. Different authors consider the importance of the body in the appraisal (Prinz, 2006; Klaus Scherer, 2009).

"Moreover, the body does not play a merely passive role in affective computing - it is not simply an output device triggered by a 'feed-forward' cognitive appraisal. Rather, the body itself influences how real, or imagined, environmental stimuli are perceived and evaluated. The body orients, physiologically 'prepares' and acts dynamically in relation to its external environment." (Lowe \& Kiryazov, 2014).

In Prinz's theory of embodied appraisal (Prinz, 2006) emotion is a perception of bodily changes which represent certain relations between the individual and the world. "Emotion represents changes in organism-environment relations by tracking changes in the body". Different emotions correspond to different body state prototypes, which are patterns of specific bodily features like skin conductance value. In this way, a change in a bodily state could be caused by a cognitive judgment (as mentioned above) or could be directly linked to perception.

All this provides one of the reasons for developing the emotion architecture presented in the thesis, which is to ground affective states in the sensory-motor states of the humanoid robot's body. More specifically, the goal is to ground higher level emotion components the PAD dimensional model. Grounding of the three components of emotions postulated in the PAD model (pleasure, arousal, and dominance) is a challenging task that has not been explored so far. The main focus in the current work is on grounding of the Arousal function and it is achieved by constraining it to the energy consumption of the robot. Planned future work about grounding of the other dimensions - Pleasure and Dominance - can be found in the last section of the thesis. 


\section{Chapter 5 Summary of the articles}

In Paper I, an analysis of the most important variables and performance criteria relevant to resource management in service robotics applications is performed. Specific attention is paid to the importance of finding proper effort of movement in the two-resource problem and energy autonomous robots. An overview of the appraisal theory of emotion is provided, with an emphasis on the role of the body in the appraisal process and grounding of emotion abilities in homeostatic processes. In Paper I is presented an affective cognitive model WASABI (Becker-Asano, 2008), based on appraisal theory of emotion with proven psychologically plausible emotion expressions in several implementations in virtual agents and robots. Paper I presents the first version of the affective cognitive architecture based on WASABI for solving two-resource problems in a framework for service robots. The arousal component of the WASABI emotion engine was grounded in energy processes of the robot body. For the initial investigation a simple "threshold-based" action selection strategy is used as a substitute for the complex deliberative reasoning modules of WASABI and the main accent of the research is on the grounding of the arousal component of PAD space in energy processes and effort of movement. Several tests are performed in an abstract scenario where the two resources - work and fuel are square areas on the ground and a simulation of a NAO humanoid "gathers" them by walking and stepping on the squares. The demonstrative runs of the system in different environments show the role of the arousal mechanism to handle urgent work events. The energy consumption dynamics have pattern -"B" described in section 2-3-1. That makes the choice of the right effort of a movement not trivial in the proposed two -resource problem.

Paper II builds on and further develops the affective architecture introduced in Paper I. In this paper the cue-deficit action selection strategy is used instead of the simple threshold based one. Empirically it is shown that this simple action selection strategy produces sustainable basic cycles in the proposed scenario for a two-resource problem and performs better than the two obvious simple strategies. The experiments are performed in scenarios that are more realistic and closer to the real-world tasks, which humanoid service robots are supposed to solve. The iCub robot should follow a ball held in random positions from a human, while not running out of energy. This scenario represents a dynamic more complex two-resource problem compared to the static one in Paper I- requiring tracking of the moving resource and 3D manipulation. Experimental data is collected from a simulated $\mathrm{iCub}$ robot. Data from the real robot is provided for comparison. The cognitive architecture uses a work utility function which from one side presents a natural performance measure of the robot task. From another side it provides cyclical continuous dynamics which allows the implementation of the bio-inspired homeostasis regulating architecture. In this paper the tests with the NAO robot from the Paper I are repeated in the new scenarios with the iCub robot. The results shows that the effect of the arousal on the performance of the robot is the same in both scenarios. An initial investigation for the architecture's extension with the expression of the robot's emotional state is performed and some ideas about how this 
ability will improve the human-robot interaction are provided. At the end of the paper, the concept of safety and its relevance to resource management and HRI is discussed.

In Paper III the work in the previous papers is extended and integrated with a more detailed examination of the role of safety in human-robot interaction. Safety is introduced as a natural third homeostatic variable for a service robot interacting with a human. Experimental validation of the relationship between arousal and effort introduced in the previous two papers is improved and extended. Experiments in the new three-resource problem is performed. The experimental results show that the architecture can handle a three-resource problem when provided with a reasonable measure of safety deficit. The arousal mechanism serves as means of embodying the cue-deficit action selection strategy into the robot's body processes. More detailed analysis of the basic cycles of the architecture are performed exploring the role of emergent behavioral properties as "opportunism" and "persistence" for the robot's adaptivity in the multi-resource scenarios. 


\section{Chapter 6 Conclusion}

The main contributions of the thesis are:

1. A detailed explanation of the resource management problem for autonomous robots is presented. Special attention is paid to the analysis of particular aspects of resource management in interaction with humans (for example effort of movement and safety relationship). An overview of the existing solutions for resource management with an emphasis on emotion cognitive architectures is provided. The major pros and cons for the different solutions are pointed out and the aspects of the solution which are related to the motivation for developing of the architecture in the thesis is shown.

2. A bio-inspired cognitive architecture for resource management for autonomous robots interacting with humans is developed. The architecture exploits the idea of grounding of ethological models of task selection through another bio-inspired affective mechanism of appraisal and arousal. The architecture contains top-down components based on descriptive ethological and psychological models of emotion and affect and is grounded in bottom-up processes: energy level and speed of movement. The architecture has some important abilities for HRI like monitoring human actions and safety control.

3. Experimental data validating the proposed architecture in scenarios of two and three resource problems is provided. The analysis of the performance of the architecture shows the role of the cue-deficit model and the grounded arousal mechanism for the efficient behavior in the presented robotic scenarios. The experiments are performed with two humanoid robot scenarios, which tries to include some of the basic necessities for service robotics. A discussion is provided of generalization of the proposed results in respect to other applications of the service robotics industry.

4. Initial investigations of the role of emotion expression / recognition in the proposed problems is presented. The architecture generates facial emotion expression based on the level of arousal. Discussion about the role of the expression recognition system has in the resource management in HRI is provided.

There are several directions, in which the thesis can be developed towards a completion of a PhD thesis:

1. The presented architecture in the thesis doesn't include any learning mechanisms for now. The lack of learning mechanisms helps pay more attention to the particular adaptive properties of the interaction of the robot and the environment and analyzing emergent behavioral patterns of the body-environment coupling. However future work can adopt learning algorithms which will adapt the basic parameters related to resource management during robot's lifetime. For example in the current implementation detecting of a cue of resource is done via a vision module which already "knows" about this resource. Ideally future versions of architecture should "embody" the cue letting the agent "discover" itself during its life time what is the mapping between robot actions and dynamics of its essential 
variables, i.e. what are the "resources" which the robot should manage and how to "sense" them in the environment. From another side in the 3D manipulator scenario (tracking a target with a the hand of the $\mathrm{iCub}$ ) where the experiments of paper II and paper III are performed, the energy which the robot should spend is dependent on the current position of the robot, and could be different for positions at the same distance to the target (the same cue). One and the same targets (end effector state) can have different kinematic and dynamic solutions which could have different energy consumption profiles and time to be performed (e.g. going upwards costs more energy or time). Therefore, rather than using a simple cue in the task selection algorithm, more complex estimation of the resource accessibility could be used related to the robot and target position. One way of implementing this is with a reinforcement learning algorithm, which takes rewards from the current level of arousal- an estimation of the state of the robot according to its resource balance. An initial hypothesis is that a "learning system" will outperform the current one.

2. Experimental data with human subjects could be useful for validating the architecture's abilities of emotion expression and recognition. A possible experimental design with the cognitive architecture implemented in a virtual robot could have four conditions with or without emotional expression/recognition in a cooperative game with a human. The hypothesis is that both emotional expression (face expressions) and recognition will outperform "non- emotional" variants. In order to validate the transfer to the real robotic world the architecture data in both cases without human player will be compared.

3. The importance of the role of CPU power in energy management is mentioned in the thesis but experimental results were not yet provided. A future development of the cognitive architecture could enable the arousal mechanisms to modulate the rate of computation of the most computational expensive module of the architecture, for example the vision module. The vision module could work on a higher rate or resolution which will require higher CPU power and energy consumption or it could be in an "low-energy" mode when the robot should spare the energy. This will be more prone to mistakes as it will provide the information with a delay affecting negatively the work performance of the robot. This is congruent with the 'tick rate hypothesis'- arousal level is coupled with the rate of the environmental sampling (Revelle \& Loftus, 1992). Initial experimental hypothesis that the cognitive architecture will improve its behavior compared to the case when the rate of vision module stays at a fixed value.

4. The architecture exploits only the arousal dimension of the PAD emotion state dynamics. An extended future version of the architecture could also elaborate the Pleasure and Dominance dimensions. Pleasure dimension could be interfaced with a reinforcement algorithm using reward function based on the resources' deficit. The Pleasure - Arousal dynamics computed now with the WASABI emotion engine can be better elaborated by providing a new component, which exploits more naturally the biological counterparts of these emotion dimensions. Dominance is related to social position of the robot. It could be connected to reflexive behavior for approach/ avoidance of certain stimuli. 


\section{Bibliography}

Arkin, R. C., \& Mackenzie, D. C. (1994). Planning to Behave: A Hybrid Deliberative/Reactive Robot Control Architecture for Mobile Manipulation. In International Symphosium on Robotics and Manufactoring (pp. 5-12).

Ashby, W. R. (1960). Design for a Brain: The Origin of Adaptive Behavior (Science Paperbacks) (p. 296). Chapman and Hall.

Avila-García, O., \& Cañamero, L. (2004). Using hormonal feedback to modulate action selection in a competitive scenario. From Animals to Animats: Proceedings of the 8th International Conference of Adaptive Behavior, 243-252.

Bar-On, R., \& Parker, J. (Eds.). (2000). The Handbook of Emotional Intelligence : Theory, Development, Assessment, and Application at Home, School and in the Workplace (p. 544). Jossey-Bass.

Becker-Asano, C. (2008). WASABI: Affect Simulation for Agents with Believable Interactivity - Volume 319 Dissertations in Artificial Intelligence (Dissertationen Zur ... in Artificial Intelligence). IOS Press.

Bicho, E., Louro, L., \& Erlhagen, W. (2010). Integrating verbal and nonverbal communication in a dynamic neural field architecture for human-robot interaction. Frontiers in Neurorobotics, 4. doi:10.3389/fnbot.2010.00005

Braitenberg, V. (1986). Vehicles: Experiments in Synthetic Psychology (p. 168). A Bradford Book.

Breazeal, C. (2004). Function Meets Style: Insights From Emotion Theory Applied to HRI. IEEE Transactions on Systems, Man and Cybernetics, Part C (Applications and Reviews), 34(2), 187-194. doi:10.1109/TSMCC.2004.826270

Breazeal, C., \& Brooks, R. (2004). Robot emotions: A functional perspective. In Who Needs Emotions. Oxford University Press.

Brooks, R. A. (1985). A Robust Layered Control System For a Mobile Robot. IEEE Journal on Robotics and Automation.

Buis, A. (2010). NASA Demonstrates Novel Ocean-Powered Underwater Vehicle. Jet Propulsion Laboratory. 
Cañamero, D. (1997). Modeling motivations and emotions as a basis for intelligent behavior. In Proceedings of the first international conference on Autonomous agents - AGENTS '97 (pp. 148-155). New York: ACM Press.

Cañamero, D. (1998). Issues in the Design of Emotional Agents. In Emotional and Intelligent: The Tangled Knot of Cognition. Proceedings of 1998 AAAI Fall Symposium.

Cañamero, L. (2005). Emotional development: recent research advances (p. 457). Oxford University Press.

Cannon, W. (1927). The James-Lange Theory of Emotions: A Critical Examination and an Alternative Theory. The American Journal of Psychology, 39, 106 - 124.

Damasio, A. (2003). Looking for Spinoza: Joy, Sorrow, and the Feeling Brain (p. 368). Mariner Books.

Damasio, A. (2012). Self Comes to Mind: Constructing the Conscious Brain (p. 416). Vintage.

Deshmukh, A., Vargas, P. A., Aylett, R., \& Brown, K. (2010). Towards Socially Constrained Power Management for Long-Term Operation of Mobile Robots. In Towards Autonomous Robotic Systems. Plymouth.

Ducatelle, F., Di Caro, G. A., Pinciroli, C., \& Gambardella, L. M. (2011). Self-organized cooperation between robotic swarms. Swarm Intelligence, 5(2), 73-96. doi:10.1007/s11721-011-0053-0

Edmondson, K. M., Fetzer, C., Karam, N. H., Stella, P., Mardesich, N., \& Mueller, R. (2007). Multijunction solar cells optimized for the Mars surface solar spectrum. In 20th Space Photovoltaic Research and Technology (SPRAT).

Gadanho, S. (2003). Learning behavior-selection by emotions and cognition in a multi-goal robot task. The Journal of Machine Learning Research, 4, 385-412.

Gadanho, S. C., \& Custódio, L. (2002). Learning Behavior-Selection in a Multi-Goal Robot Task. In NAISO ICAIS.

Gadanho, S. C., \& Hallam, J. (2002). Robot Learning Driven by Emotions. Adaptive Behavior, 9(1), 42-64.

Hallam, B., \& Hayes, G. (1992). Comparing Robot and Animal Behaviour. University of Edinburgh.

Hatfield, E., Cacioppo, J. T., \& Rapson, R. L. (1994). Emotional Contagion (Studies in Emotion and Social Interaction). Cambridge University Press.

Hoff, N. (2011). Multi-Robot Foraging for Swarms of Simple Robots. Harvard University. 
Hoyt, D. F., \& Taylor, C. R. (1981). Gait and the energetics of locomotion in horses. Nature, 292(5820), 239-240.

Johansson, B., \& Balkenius, C. (2006). An Experimental Study of Anticipation in Simple Robot Navigation. In M. V Butz, O. Sigaud, G. Pezzulo, \& G. Baldassarre (Eds.), $S A B$ ABiALS (Vol. 4520, pp. 365-378). Springer.

Jung, B., Nies, D., \& Sukhatme, G. S. (2002). Staying alive longer: Autonomous robot recharging put to the test.

Kelly, I., Holland, O., Scull, M., \& McFarland, D. (1999). Artificial Autonomy in the Natural World: Building a Robot Predator. In Advances in Artificial Life.

Klappenbach, L. (2013). heterotroph. TheFreeDictionary.com.

Kolíbal, Z., \& Smetanová, A. (2010). Experimental implementation of energy optimization by robot movement. In 2010 IEEE 19th International Workshop on Robotics in Alpe-AdriaDanube Region (p. 333,339).

Kulić, D. (2006, May 1). Safety for human-robot interaction. University of British Columbia.

Lazarus, R. S. (1994). Emotion and Adaptation (p. 576). Oxford University Press.

Lowe, R., Herrera, C., Morse, A., \& Ziemke, T. (2007). The Embodied Dynamics of Emotion, Appraisal and Attention. Attention in Cognitive Systems. Theories and Systems from an Interdisciplinary Viewpoint, 4840, 1-20.

Lowe, R., \& Kiryazov, K. (2014). Grounding Emotions and Autonomous Behaviour in Robots : A Minimalist Approach. Sumbitted for publication.

Lowe, R., Montebelli, A., Ieropoulos, I., Greenman, J., Melhuish, C., \& Ziemke, T. (2010). Grounding Motivation in Energy Autonomy: A Study of Artificial Metabolism Constrained Robot Dynamics. Artificial Life XII : Proceedings of the Twelfth International Conference on the Synthesis and Simulation of Living Systems.

Ma, S. (1999). Time optimal control of manipulators with limit heat characteristics of actuators. In Proceedings 1999 IEEE/RSJ International Conference on Intelligent Robots and Systems. Human and Environment Friendly Robots with High Intelligence and Emotional Quotients (Cat. No.99CH36289) (Vol. 1, pp. 338-343). IEEE.

Mandel, C., Huebner, K., Vierhuff, T., \& Christian, M. (2005). Towards an Autonomous Wheelchair: Cognitive Aspects in Service Robotics. In Towards Autonomous Robotic Systems (pp. 165 - 172).

McFarland, D. (2008). Guilty Robots, Happy Dogs: The Question of Alien Minds (p. 256). Oxford University Press, USA.

McFarland, D., \& Bösser, T. (1993). Intelligent Behavior in Animals and Robots (Complex Adaptive Systems) (p. 322). A Bradford Book. 
McFarland, D., \& Spier, E. (1997). Basic Cycles, Utility and Opportunism in Self-Sufficient Robots. Robotics and Autonomous Systems, 20, 179-190.

Melhuish, C., Ieropoulos, I., Greenman, J., \& Horsfield, I. (2006). Energetically autonomous robots: Food for thought. Autonomous Robots, 21(3), 187-198.

Michaud, F., \& Audet, J. (2001). Using motives and artificial emotions for long-term activity of an autonomous robot. In Proceedings of the fifth international conference on Autonomous agents - AGENTS '01 (pp. 188-189). New York, New York, USA: ACM Press.

Michel, O., \& Rohrer, F. (2008). The Rat's Life benchmark. In Proceedings of the 8th Workshop on Performance Metrics for Intelligent Systems - PerMIS '08 (p. 43). New York, New York, USA: ACM Press. doi:10.1145/1774674.1774682

Ngo, T., \& Schioler, H. (2006). Sociable Mobile Robots through Self-maintained Energy. In 2006 IEEE International Conference on Systems, Man and Cybernetics (Vol. 3, pp. 2012-2017). IEEE. doi:10.1109/ICSMC.2006.385026

Novitzky, M., Pippin, C., Collins, T. R., Balch, T. R., \& West, M. E. (2012). Bio-inspired multi-robot communication through behavior recognition. In 2012 IEEE International Conference on Robotics and Biomimetics (ROBIO) (pp. 771-776). IEEE.

Oatley, K., \& Johnson-laird, P. N. (1987). Towards a Cognitive Theory of Emotions. Cognition \& Emotion, 1(1), 29-50. doi:10.1080/02699938708408362

Parker, G., \& Zbeda, R. (2007). Learning navigation for recharging a self-sufficient colony robot. In 2007 IEEE International Conference on Systems, Man and Cybernetics (pp. 734-740). IEEE. doi:10.1109/ICSMC.2007.4413695

Prinz, J. J. (2006). Gut Reactions: A Perceptual Theory of Emotion (Philosophy of Mind) (p. 288). Oxford University Press, USA.

Radice, G., \& McInnes, C. R. (2003, June 13). Autonomous behavioural algorithm for space applications. Aeronautical Journal.

Rani, P., Sarkar, N., Smith, C. A., \& Kirby, L. D. (2004). Anxiety detecting robotic system towards implicit human-robot collaboration. Robotica, 22(1), 85-95.

Revelle, W., \& Loftus, D. A. (1992). The implications of arousal effects for the study of affect and memory. In Handbook of emotion and memory.

Sandini, G., Metta, G., \& Vernon, D. (2007). The iCub cognitive humanoid robot: an opensystem research platform for enactive cognition. 50 Years of Artificial Intelligence, 4850, 358-369.

Scherer, K. (1984). On the nature and function of emotion: A component process approach. In K. Scherer \& P. Ekman (Eds.), Approaches To Emotion (pp. 293 - 317). 
Scherer, K. (2009). Emotions are emergent processes: they require a dynamic computational architecture. Philosophical Transactions of the Royal Society of London. Series B, Biological Sciences, 364(1535), 3459-74. doi:10.1098/rstb.2009.0141

Sibly, R. (1975). How incentive and deficit determine feeding tendency. Animal Behaviour, $437-466$.

Silver, R., \& Lesauter, J. (2008). Circadian and homeostatic factors in arousal. Annals of the New York Academy of Sciences, 1129, 263-74. doi:10.1196/annals.1417.032

Smith, R. N., Das, J., Hine, G., Anderson, W., \& Sukhatme, G. S. (2011, June 1). Predicting wave glider speed from environmental measurements. Proceedings of MTS/IEEE Oceans 2011. IEEE.

Spier, E., \& McFarland, D. (1997). Possibly Optimal Decision-Making Under Selfsufficiency and Autonomy. Journal of Theoretical Biology, 189, 189-317.

Thill, S., \& Lowe, R. (2012). On the Functional Contributions of Emotion Mechanisms to (Artificial) Cognition and Intelligence. In J. Bach, B. Goertzel, \& M. Iklé (Eds.), Artificial General Intelligence SE - 33 (Vol. 7716, pp. 322-331). Springer Berlin Heidelberg.

Toal, D., Flanagan, C., Jones, C., \& Strunz, B. (1996). Subsumption Architecture For The Control Of Robots. In 13th Irish Manufacturing Conference.

Watson, J. B., \& Morgan, J. J. B. (1917). Emotional Reactions and Psychological Experimentation. The American Journal of Psychology, 28(2), pp. 163-174.

Wawerla, J. (2010, June 1). Task-switching for self-sufficient robots. Simon Fraser University.

Wawerla, J., \& Vaughan, R. (2008). Optimal robot recharging strategies for time discounted labour. In Artificial Life XI: Proceedings of the Eleventh International Conference on the Simulation and Synthesis of Living Systems (pp. 670 - 677). MIT Press, Cambridge, MA.

Wawerla, J., \& Vaughan, R. T. (2009). Robot task switching under diminishing returns. In 2009 IEEE/RSJ International Conference on Intelligent Robots and Systems (pp. 50335038). IEEE. doi:10.1109/IROS.2009.5354126

Wettergreen, D., Tompkins, P., Urmson, C., Wagner, M. D., \& Whittaker, W. (2005). SunSynchronous Robotic Exploration: Technical Description and Field Experimentation. The International Journal of Robotics Research, 24(1), 3-30.

Wikipedia. (2013). Energetically Autonomous Tactical Robot. Retrieved from http://en.wikipedia.org/wiki/Energetically_Autonomous_Tactical_Robot

Zebrowsk, P., \& Vaughan, R. T. (2005). Recharging robot teams: A tanker approach. In ICAR '05. Proceedings., 12th International Conference on Advanced Robotics, 2005. (pp. 803810). IEEE. doi:10.1109/ICAR.2005.1507500 


\section{Papers}

The articles associated with this thesis have been removed for copyright reasons. For more details about these see:

http://urn.kb.se/resolve?urn=urn:nbn:se:liu:diva-105344 


\section{Department of Computer and Information Science \\ Linköpings universitet}

\section{Licentiate Theses}

\section{Linköpings Studies in Science and Technology Faculty of Arts and Sciences}

No 17

No 28

No 29

No 48

No 52

No 60

No 71

No 72

No 73

No 74

No 104

No 108

No 111

No 113

No 118

No 126

No 127

No 139

No 140

No 146

No 150

No 165

No 166

No 174

No 177

No 181

No 184

No 187

No 189

No 196

No 197

No 203

No 212

No 230

No 237

No 250

No 253

No 260

No 283

No 298

No 318

No 319

No 326

No 328

No 333

No 335

No 348

No 352

No 371

No 378

Vojin Plavsic: Interleaved Processing of Non-Numerical Data Stored on a Cyclic Memory. (Available at: FOA, Box 1165, S-581 11 Linköping, Sweden. FOA Report B30062E)

Arne Jönsson, Mikael Patel: An Interactive Flowcharting Technique for Communicating and Realizing Algorithms, 1984.

Johnny Eckerland: Retargeting of an Incremental Code Generator, 1984.

Henrik Nordin: On the Use of Typical Cases for Knowledge-Based Consultation and Teaching, 1985.

Zebo Peng: Steps Towards the Formalization of Designing VLSI Systems, 1985.

Johan Fagerström: Simulation and Evaluation of Architecture based on Asynchronous Processes, 1985.

Jalal Maleki: ICONStraint, A Dependency Directed Constraint Maintenance System, 1987.

Tony Larsson: On the Specification and Verification of VLSI Systems, 1986.

Ola Strömfors: A Structure Editor for Documents and Programs, 1986.

Christos Levcopoulos: New Results about the Approximation Behavior of the Greedy Triangulation, 1986.

Shamsul I. Chowdhury: Statistical Expert Systems - a Special Application Area for Knowledge-Based Computer Methodology, 1987.

Rober Bilos: Incremental Scanning and Token-Based Editing, 1987.

Hans Block: SPORT-SORT Sorting Algorithms and Sport Tournaments, 1987.

Ralph Rönnquist: Network and Lattice Based Approaches to the Representation of Knowledge, 1987.

Mariam Kamkar, Nahid Shahmehri: Affect-Chaining in Program Flow Analysis Applied to Queries of Programs, 1987.

Dan Strömberg: Transfer and Distribution of Application Programs, 1987.

Kristian Sandahl: Case Studies in Knowledge Acquisition, Migration and User Acceptance of Expert Systems, 1987.

Christer Bäckström: Reasoning about Interdependent Actions, 1988.

Mats Wirén: On Control Strategies and Incrementality in Unification-Based Chart Parsing, 1988.

Johan Hultman: A Software System for Defining and Controlling Actions in a Mechanical System, 1988.

Tim Hansen: Diagnosing Faults using Knowledge about Malfunctioning Behavior, 1988.

Jonas Löwgren: Supporting Design and Management of Expert System User Interfaces, 1989.

Ola Petersson: On Adaptive Sorting in Sequential and Parallel Models, 1989.

Yngve Larsson: Dynamic Configuration in a Distributed Environment, 1989.

Peter Åberg: Design of a Multiple View Presentation and Interaction Manager, 1989.

Henrik Eriksson: A Study in Domain-Oriented Tool Support for Knowledge Acquisition, 1989.

Ivan Rankin: The Deep Generation of Text in Expert Critiquing Systems, 1989.

Simin Nadjm-Tehrani: Contributions to the Declarative Approach to Debugging Prolog Programs, 1989.

Magnus Merkel: Temporal Information in Natural Language, 1989.

Ulf Nilsson: A Systematic Approach to Abstract Interpretation of Logic Programs, 1989.

Staffan Bonnier: Horn Clause Logic with External Procedures: Towards a Theoretical Framework, 1989.

Christer Hansson: A Prototype System for Logical Reasoning about Time and Action, 1990.

Björn Fjellborg: An Approach to Extraction of Pipeline Structures for VLSI High-Level Synthesis, 1990.

Patrick Doherty: A Three-Valued Approach to Non-Monotonic Reasoning, 1990.

Tomas Sokolnicki: Coaching Partial Plans: An Approach to Knowledge-Based Tutoring, 1990.

Lars Strömberg: Postmortem Debugging of Distributed Systems, 1990.

Torbjörn Näslund: SLDFA-Resolution - Computing Answers for Negative Queries, 1990.

Peter D. Holmes: Using Connectivity Graphs to Support Map-Related Reasoning, 1991.

Olof Johansson: Improving Implementation of Graphical User Interfaces for Object-Oriented Knowledge- Bases, 1991.

Rolf G Larsson: Aktivitetsbaserad kalkylering i ett nytt ekonomisystem, 1991.

Lena Srömbäck: Studies in Extended Unification-Based Formalism for Linguistic Description: An Algorithm for Feature Structures with Disjunction and a Proposal for Flexible Systems, 1992.

Mikael Pettersson: DML-A Language and System for the Generation of Efficient Compilers from Denotational Specification, 1992.

Andreas Kågedal: Logic Programming with External Procedures: an Implementation, 1992.

Patrick Lambrix: Aspects of Version Management of Composite Objects, 1992.

Xinli Gu: Testability Analysis and Improvement in High-Level Synthesis Systems, 1992.

Torbjörn Näslund: On the Role of Evaluations in Iterative Development of Managerial Support Systems, 1992.

Ulf Cederling: Industrial Software Development - a Case Study, 1992.

Magnus Morin: Predictable Cyclic Computations in Autonomous Systems: A Computational Model and Implementation, 1992.

Mehran Noghabai: Evaluation of Strategic Investments in Information Technology, 1993.

Mats Larsson: A Transformational Approach to Formal Digital System Design, 1993. 
Johan Ringström: Compiler Generation for Parallel Languages from Denotational Specifications, 1993. Michael Jansson: Propagation of Change in an Intelligent Information System, 1993. Jonni Harrius: An Architecture and a Knowledge Representation Model for Expert Critiquing Systems, 1993. Per Österling: Symbolic Modelling of the Dynamic Environments of Autonomous Agents, 1993. Johan Boye: Dependency-based Groudness Analysis of Functional Logic Programs, 1993.

Lars Degerstedt: Tabulated Resolution for Well Founded Semantics, 1993.

Anna Moberg: Satellitkontor - en studie av kommunikationsmönster vid arbete på distans, 1993.

Peter Carlsson: Separation av företagsledning och finansiering - fallstudier av företagsledarutköp ur ett agentteoretiskt perspektiv, 1994.

Camilla Sjöström: Revision och lagreglering - ett historiskt perspektiv, 1994.

Cecilia Sjöberg: Voices in Design: Argumentation in Participatory Development, 1994.

Lars Viklund: Contributions to a High-level Programming Environment for a Scientific Computing, 1994.

Peter Loborg: Error Recovery Support in Manufacturing Control Systems, 1994.

Owen Eriksson: Informationssystem med verksamhetskvalitet - utvärdering baserat på ett verksamhetsinriktat och samskapande perspektiv, 1994.

Karin Pettersson: Informationssystemstrukturering, ansvarsfördelning och användarinflytande - En komparativ studie med utgångspunkt i två informationssystemstrategier, 1994.

Lars Poignant: Informationsteknologi och företagsetablering - Effekter på produktivitet och region, 1994.

Gustav Fahl: Object Views of Relational Data in Multidatabase Systems, 1994.

Henrik Nilsson: A Declarative Approach to Debugging for Lazy Functional Languages, 1994.

Jonas Lind: Creditor - Firm Relations: an Interdisciplinary Analysis, 1994.

Martin Sköld: Active Rules based on Object Relational Queries - Efficient Change Monitoring Techniques, 1994.

Pär Carlshamre: A Collaborative Approach to Usability Engineering: Technical Communicators and System Developers in Usability-Oriented Systems Development, 1994.

Stefan Cronholm: Varför CASE-verktyg i systemutveckling? - En motiv- och konsekvensstudie avseende arbetssätt och arbetsformer, 1994.

Mikael Lindvall: A Study of Traceability in Object-Oriented Systems Development, 1994.

Fredrik Nilsson: Strategi och ekonomisk styrning - En studie av Sandviks förvärv av Bahco Verktyg, 1994.

Hans Olsén: Collage Induction: Proving Properties of Logic Programs by Program Synthesis, 1994.

Lars Karlsson: Specification and Synthesis of Plans Using the Features and Fluents Framework, 1995.

Ulf Söderman: On Conceptual Modelling of Mode Switching Systems, 1995.

Choong-ho Yi: Reasoning about Concurrent Actions in the Trajectory Semantics, 1995.

Bo Lagerström: Successiv resultatavräkning av pågående arbeten. - Fallstudier i tre byggföretag, 1995.

Peter Jonsson: Complexity of State-Variable Planning under Structural Restrictions, 1995.

Anders Avdic: Arbetsintegrerad systemutveckling med kalkylprogram, 1995.

Eva L Ragnemalm: Towards Student Modelling through Collaborative Dialogue with a Learning Companion, 1995.

Eva Toller: Contributions to Parallel Multiparadigm Languages: Combining Object-Oriented and Rule-Based Programming, 1995.

Erik Stoy: A Petri Net Based Unified Representation for Hardware/Software Co-Design, 1995.

Johan Herber: Environment Support for Building Structured Mathematical Models, 1995.

Stefan Svenberg: Structure-Driven Derivation of Inter-Lingual Functor-Argument Trees for Multi-Lingual Generation, 1995.

Hee-Cheol Kim: Prediction and Postdiction under Uncertainty, 1995.

Dan Fristedt: Metoder i användning - mot förbättring av systemutveckling genom situationell metodkunskap och metodanalys, 1995.

Malin Bergvall: Systemförvaltning i praktiken - en kvalitativ studie avseende centrala begrepp, aktiviteter och ansvarsroller, 1995.

Joachim Karlsson: Towards a Strategy for Software Requirements Selection, 1995.

Jakob Axelsson: Schedulability-Driven Partitioning of Heterogeneous Real-Time Systems, 1995.

Göran Forslund: Toward Cooperative Advice-Giving Systems: The Expert Systems Experience, 1995.

Jörgen Andersson: Bilder av småföretagares ekonomistyrning, 1995.

Staffan Flodin: Efficient Management of Object-Oriented Queries with Late Binding, 1996.

Vadim Engelson: An Approach to Automatic Construction of Graphical User Interfaces for Applications in Scientific Computing, 1996.

Magnus Werner : Multidatabase Integration using Polymorphic Queries and Views, 1996.

Mikael Lind: Affärsprocessinriktad förändringsanalys - utveckling och tillämpning av synsätt och metod, 1996.

Jonas Hallberg: High-Level Synthesis under Local Timing Constraints, 1996.

Kristina Larsen: Förutsättningar och begränsningar för arbete på distans - erfarenheter från fyra svenska företag. 1996.

Mikael Johansson: Quality Functions for Requirements Engineering Methods, 1996.

Patrik Nordling: The Simulation of Rolling Bearing Dynamics on Parallel Computers, 1996.

Anders Ekman: Exploration of Polygonal Environments, 1996.

Niclas Andersson: Compilation of Mathematical Models to Parallel Code, 1996. 
Johan Jenvald: Simulation and Data Collection in Battle Training, 1996.

Niclas OhIsson: Software Quality Engineering by Early Identification of Fault-Prone Modules, 1996.

Mikael Ericsson: Commenting Systems as Design Support-A Wizard-of-Oz Study, 1996.

Jörgen Lindström: Chefers användning av kommunikationsteknik, 1996.

Esa Falkenroth: Data Management in Control Applications - A Proposal Based on Active Database Systems, 1996.

Niclas Wahllöf: A Default Extension to Description Logics and its Applications, 1996.

Annika Larsson: Ekonomisk Styrning och Organisatorisk Passion - ett interaktivt perspektiv, 1997.

Ling Lin: A Value-based Indexing Technique for Time Sequences, 1997.

Rego Granlund: $C^{3}$ Fire - A Microworld Supporting Emergency Management Training, 1997.

Peter Ingels: A Robust Text Processing Technique Applied to Lexical Error Recovery, 1997.

Per-Arne Persson: Toward a Grounded Theory for Support of Command and Control in Military Coalitions, 1997. Jonas S Karlsson: A Scalable Data Structure for a Parallel Data Server, 1997.

Carita Åbom: Videomötesteknik i olika affärssituationer - möjligheter och hinder, 1997.

Tommy Wedlund: Att skapa en företagsanpassad systemutvecklingsmodell - genom rekonstruktion, värdering och vidareutveckling i T50-bolag inom ABB, 1997.

Silvia Coradeschi: A Decision-Mechanism for Reactive and Coordinated Agents, 1997.

Jan Ollinen: Det flexibla kontorets utveckling på Digital - Ett stöd för multiflex? 1997.

David Byers: Towards Estimating Software Testability Using Static Analysis, 1997.

Fredrik Eklund: Declarative Error Diagnosis of GAPLog Programs, 1997.

Gunilla Ivefors: Krigsspel och Informationsteknik inför en oförutsägbar framtid, 1997.

Jens-Olof Lindh: Analysing Traffic Safety from a Case-Based Reasoning Perspective, 1997

Jukka Mäki-Turja:. Smalltalk - a suitable Real-Time Language, 1997.

Juha Takkinen: CAFE: Towards a Conceptual Model for Information Management in Electronic Mail, 1997.

Man Lin: Formal Analysis of Reactive Rule-based Programs, 1997.

Mats Gustafsson: Bringing Role-Based Access Control to Distributed Systems, 1997.

Boris Karlsson: Metodanalys för förståelse och utveckling av systemutvecklingsverksamhet. Analys och värdering av systemutvecklingsmodeller och dess användning, 1997.

Marcus Bjäreland: Two Aspects of Automating Logics of Action and Change - Regression and Tractability, 1998.

Jan Håkegård: Hierarchical Test Architecture and Board-Level Test Controller Synthesis, 1998.

Per-Ove Zetterlund: Normering av svensk redovisning - En studie av tillkomsten av Redovisningsrådets rekommendation om koncernredovisning (RR01:91), 1998.

Jimmy Tjäder: Projektledaren \& planen - en studie av projektledning i tre installations- och systemutvecklingsprojekt, 1998.

Ulf Melin: Informationssystem vid ökad affärs- och processorientering - egenskaper, strategier och utveckling, 1998.

Tim Heyer: COMPASS: Introduction of Formal Methods in Code Development and Inspection, 1998.

Patrik Hägglund: Programming Languages for Computer Algebra, 1998.

Marie-Therese Christiansson: Inter-organisatorisk verksamhetsutveckling - metoder som stöd vid utveckling av partnerskap och informationssystem, 1998.

Christina Wennestam: Information om immateriella resurser. Investeringar i forskning och utveckling samt i personal inom skogsindustrin, 1998.

Joakim Gustafsson: Extending Temporal Action Logic for Ramification and Concurrency, 1998.

Henrik André-Jönsson: Indexing time-series data using text indexing methods, 1999.

Erik Larsson: High-Level Testability Analysis and Enhancement Techniques, 1998.

Carl-Johan Westin: Informationsförsörjning: en fråga om ansvar - aktiviteter och uppdrag i fem stora svenska organisationers operativa informationsförsörjning, 1998.

Åse Jansson: Miljöhänsyn - en del i företags styrning, 1998.

Thomas Padron-McCarthy: Performance-Polymorphic Declarative Queries, 1998.

Anders Bäckström: Värdeskapande kreditgivning - Kreditriskhantering ur ett agentteoretiskt perspektiv, 1998.

Ulf Seigerroth: Integration av förändringsmetoder - en modell för välgrundad metodintegration, 1999.

Fredrik Öberg: Object-Oriented Frameworks - A New Strategy for Case Tool Development, 1998.

Jonas Mellin: Predictable Event Monitoring, 1998.

Joakim Eriksson: Specifying and Managing Rules in an Active Real-Time Database System, 1998.

Bengt E W Andersson: Samverkande informationssystem mellan aktörer i offentliga åtaganden - En teori om aktörsarenor i samverkan om utbyte av information, 1998.

Pawel Pietrzak: Static Incorrectness Diagnosis of CLP (FD), 1999

Tobias Ritzau: Real-Time Reference Counting in RT-Java, 1999.

Anders Ferntoft: Elektronisk affärskommunikation - kontaktkostnader och kontaktprocesser mellan kunder och leverantörer på producentmarknader, 1999.

Jo Skåmedal: Arbete på distans och arbetsformens påverkan på resor och resmönster, 1999 .

Johan Alvehus: Mötets metaforer. En studie av berättelser om möten, 1999. 
Magnus Lindahl: Bankens villkor i låneavtal vid kreditgivning till högt belånade företagsförvärv: En studie ur ett agentteoretiskt perspektiv, 2000.

Martin V. Howard: Designing dynamic visualizations of temporal data, 1999

Jesper Andersson: Towards Reactive Software Architectures, 1999.

Anders Henriksson: Unique kernel diagnosis, 1999.

Pär J. Ågerfalk: Pragmatization of Information Systems - A Theoretical and Methodological Outline, 1999.

Charlotte Björkegren: Learning for the next project - Bearers and barriers in knowledge transfer within an organisation, 1999.

Håkan Nilsson: Informationsteknik som drivkraft i granskningsprocessen - En studie av fyra revisionsbyråer, 2000.

Erik Berglund: Use-Oriented Documentation in Software Development, 1999.

Klas Gäre: Verksamhetsförändringar i samband med IS-införande, 1999.

Anders Subotic: Software Quality Inspection, 1999.

Svein Bergum: Managerial communication in telework, 2000.

Flavius Gruian: Energy-Aware Design of Digital Systems, 2000.

Karin Hedström: Kunskapsanvändning och kunskapsutveckling hos verksamhetskonsulter - Erfarenheter från ett FOU-samarbete, 2000.

Linda Askenäs: Affärssystemet - En studie om teknikens aktiva och passiva roll i en organisation, 2000.

Jean Paul Meynard: Control of industrial robots through high-level task programming, 2000.

Lars Hult: Publika Gränsytor - ett designexempel, 2000.

Paul Pop: Scheduling and Communication Synthesis for Distributed Real-Time Systems, 2000.

Göran Hultgren: Nätverksinriktad Förändringsanalys - perspektiv och metoder som stöd för förståelse och utveckling av affärsrelationer och informationssystem, 2000.

Magnus Kald: The role of management control systems in strategic business units, 2000.

Mikael Cäker: Vad kostar kunden? Modeller för intern redovisning, 2000.

Ewa Braf: Organisationers kunskapsverksamheter - en kritisk studie av "knowledge management", 2000.

Henrik Lindberg: Webbaserade affärsprocesser - Möjligheter och begränsningar, 2000.

Benneth Christiansson: Att komponentbasera informationssystem - Vad säger teori och praktik?, 2000.

Ola Pettersson: Deliberation in a Mobile Robot, 2000.

Dan Lawesson: Towards Behavioral Model Fault Isolation for Object Oriented Control Systems, 2000.

Johan Moe: Execution Tracing of Large Distributed Systems, 2001.

Yuxiao Zhao: XML-based Frameworks for Internet Commerce and an Implementation of B2B e-procurement, 2001 .

Annika Flycht-Eriksson: Domain Knowledge Management in Information-providing Dialogue systems, 2001.

Per-Arne Segerkvist: Webbaserade imaginära organisationers samverkansformer: Informationssystemarkitektur och aktörssamverkan som förutsättningar för affärsprocesser, 2001.

Stefan Svarén: Styrning av investeringar i divisionaliserade företag - Ett koncernperspektiv, 2001

Lin Han: Secure and Scalable E-Service Software Delivery, 2001.

Emma Hansson: Optionsprogram för anställda - en studie av svenska börsföretag, 2001.

Susanne Odar: IT som stöd för strategiska beslut, en studie av datorimplementerade modeller av verksamhet som stöd för beslut om anskaffning av JAS 1982, 2002.

Stefan Holgersson: IT-system och filtrering av verksamhetskunskap - kvalitetsproblem vid analyser och beslutsfattande som bygger på uppgifter hämtade från polisens IT-system, 2001.

Per Oscarsson: Informationssäkerhet i verksamheter - begrepp och modeller som stöd för förståelse av informationssäkerhet och dess hantering, 2001.

Luis Alejandro Cortes: A Petri Net Based Modeling and Verification Technique for Real-Time Embedded Systems, 2001.

Niklas Sandell: Redovisning i skuggan av en bankkris - Värdering av fastigheter. 2001.

Fredrik Elg: Ett dynamiskt perspektiv på individuella skillnader av heuristisk kompetens, intelligens, mentala modeller, mål och konfidens i kontroll av mikrovärlden Moro, 2002.

Peter Aronsson: Automatic Parallelization of Simulation Code from Equation Based Simulation Languages, 2002. Bourhane Kadmiry: Fuzzy Control of Unmanned Helicopter, 2002.

Patrik Haslum: Prediction as a Knowledge Representation Problem: A Case Study in Model Design, 2002.

Robert Sevenius: On the instruments of governance - A law \& economics study of capital instruments in limited liability companies, 2002.

Johan Petersson: Lokala elektroniska marknadsplatser - informationssystem för platsbundna affärer, 2002.

Peter Bunus: Debugging and Structural Analysis of Declarative Equation-Based Languages, 2002.

Gert Jervan: High-Level Test Generation and Built-In Self-Test Techniques for Digital Systems, 2002.

Fredrika Berglund: Management Control and Strategy - a Case Study of Pharmaceutical Drug Development, 2002.

Fredrik Karlsson: Meta-Method for Method Configuration - A Rational Unified Process Case, 2002.

Sorin Manolache: Schedulability Analysis of Real-Time Systems with Stochastic Task Execution Times, 2002.

Diana Szentiványi: Performance and Availability Trade-offs in Fault-Tolerant Middleware, 2002.

Iakov Nakhimovski: Modeling and Simulation of Contacting Flexible Bodies in Multibody Systems, 2002.

Levon Saldamli: PDEModelica - Towards a High-Level Language for Modeling with Partial Differential Equations, 2002.

Almut Herzog: Secure Execution Environment for Java Electronic Services, 2002. 
No 1130

No 1138

No 1149

No 1156

No 1162

No 1165

FiF-a 84

No 1166

No 1167

No 1168 FiF-a 85

No 1171

FiF-a 86

No 1172

No 1183

No 1184

No 1185

Jon Edvardsson: Contributions to Program- and Specification-based Test Data Generation, 2002.

Anders Arpteg: Adaptive Semi-structured Information Extraction, 2002.

Andrzej Bednarski: A Dynamic Programming Approach to Optimal Retargetable Code Generation for Irregular Architectures, 2002.

Mattias Arvola: Good to use! : Use quality of multi-user applications in the home, 2003.

Lennart Ljung: Utveckling av en projektivitetsmodell - om organisationers förmåga att tillämpa projektarbetsformen, 2003.

Pernilla Qvarfordt: User experience of spoken feedback in multimodal interaction, 2003.

Alexander Siemers: Visualization of Dynamic Multibody Simulation With Special Reference to Contacts, 2003.

Jens Gustavsson: Towards Unanticipated Runtime Software Evolution, 2003.

Calin Curescu: Adaptive QoS-aware Resource Allocation for Wireless Networks, 2003.

Anna Andersson: Management Information Systems in Process-oriented Healthcare Organisations, 2003.

Björn Johansson: Feedforward Control in Dynamic Situations, 2003.

Traian Pop: Scheduling and Optimisation of Heterogeneous Time/Event-Triggered Distributed Embedded Systems, 2003.

Britt-Marie Johansson: Kundkommunikation på distans - en studie om kommunikationsmediets betydelse i affärstransaktioner, 2003.

Aleksandra Tešanovic: Towards Aspectual Component-Based Real-Time System Development, 2003.

Arja Vainio-Larsson: Designing for Use in a Future Context - Five Case Studies in Retrospect, 2003.

Peter Nilsson: Svenska bankers redovisningsval vid reservering för befarade kreditförluster - En studie vid införandet av nya redovisningsregler, 2003.

Fredrik Ericsson: Information Technology for Learning and Acquiring of Work Knowledge, 2003. Marcus Comstedt: Towards Fine-Grained Binary Composition through Link Time Weaving, 2003.

Åsa Hedenskog: Increasing the Automation of Radio Network Control, 2003.

Claudiu Duma: Security and Efficiency Tradeoffs in Multicast Group Key Management, 2003.

Emma Eliason: Effektanalys av IT-systems handlingsutrymme, 2003.

Carl Cederberg: Experiments in Indirect Fault Injection with Open Source and Industrial Software, 2003.

Daniel Karlsson: Towards Formal Verification in a Component-based Reuse Methodology, 2003.

Anders Hjalmarsson: Att etablera och vidmakthålla förbättringsverksamhet - behovet av koordination och interaktion vid förändring av systemutvecklingsverksamheter, 2004.

Pontus Johansson: Design and Development of Recommender Dialogue Systems, 2004.

Charlotte Stoltz: Calling for Call Centres - A Study of Call Centre Locations in a Swedish Rural Region, 2004.

Björn Johansson: Deciding on Using Application Service Provision in SMEs, 2004.

Genevieve Gorrell: Language Modelling and Error Handling in Spoken Dialogue Systems, 2004.

Ulf Johansson: Rule Extraction - the Key to Accurate and Comprehensible Data Mining Models, 2004.

Sonia Sangari: Computational Models of Some Communicative Head Movements, 2004.

Hans Nässla: Intra-Family Information Flow and Prospects for Communication Systems, 2004.

Henrik Sällberg: On the value of customer loyalty programs - A study of point programs and switching costs, 2004.

Ulf Larsson: Designarbete i dialog - karaktärisering av interaktionen mellan användare och utvecklare i en systemutvecklingsprocess, 2004.

Andreas Borg: Contribution to Management and Validation of Non-Functional Requirements, 2004.

Per-Ola Kristensson: Large Vocabulary Shorthand Writing on Stylus Keyboard, 2004.

Pär-Anders Albinsson: Interacting with Command and Control Systems: Tools for Operators and Designers, 2004.

Ioan Chisalita: Safety-Oriented Communication in Mobile Networks for Vehicles, 2004.

Thomas Gustafsson: Maintaining Data Consistency in Embedded Databases for Vehicular Systems, 2004.

Vaida Jakoniené: A Study in Integrating Multiple Biological Data Sources, 2005.

Abdil Rashid Mohamed: High-Level Techniques for Built-In Self-Test Resources Optimization, 2005.

Adrian Pop: Contributions to Meta-Modeling Tools and Methods, 2005.

Fidel Vascós Palacios: On the information exchange between physicians and social insurance officers in the sick leave process: an Activity Theoretical perspective, 2005.

Jenny Lagsten: Verksamhetsutvecklande utvärdering i informationssystemprojekt, 2005.

Emma Larsdotter Nilsson: Modeling, Simulation, and Visualization of Metabolic Pathways Using Modelica, 2005.

Christina Keller: Virtual Learning Environments in higher education. A study of students' acceptance of educational technology, 2005.

Cécile Åberg: Integration of organizational workflows and the Semantic Web, 2005.

Anders Forsman: Standardisering som grund för informationssamverkan och IT-tjänster - En fallstudie baserad på trafikinformationstjänsten RDS-TMC, 2005.

\section{Yu-Hsing Huang: A systemic traffic accident model, 2005.}

Jan Olausson: Att modellera uppdrag
transaktionsintensiva verksamheter, 2005.

Petter Ahlström: Affärsstrategier för seniorbostadsmarknaden, 2005.

Mathias Cöster: Beyond IT and Productivity - How Digitization Transformed the Graphic Industry, 2005.

Åsa Horzella: Beyond IT and Productivity - Effects of Digitized Information Flows in Grocery Distribution, 2005.

Maria Kollberg: Beyond IT and Productivity - Effects of Digitized Information Flows in the Logging Industry, 2005.

No 1190 David Dinka: Role and Identity - Experience of technology in professional settings, 2005. 
Andreas Hansson: Increasing the Storage Capacity of Recursive Auto-associative Memory by Segmenting Data, 2005.

No 1192

No 1194

No 1204

No 1206

No 1207

No 1209

No 1225

No 1228

No 1229

No 1231

No 1233

No 1244

No 1248

No 1263

FiF-a 90

No 1272

No 1277

No 1283

FiF-a 91

No 1286

No 1293

No 1302

No 1303

No 1305

No 1306

No 1307

No 1309

No 1312

No 1313

No 1317

No 1320

No 1323

No 1329

No 1331

No 1332

No 1333

No 1337

No 1339

No 1351

No 1353

No 1356

No 1359

No 1361

No 1363

No 1371

No 1373

No 1381

No 1386

No 1387

No 1392

No 1393

No 1401

No 1410

No 1421

No 1427

No 1450

No 1459

No 1466
Nicklas Bergfeldt: Towards Detached Communication for Robot Cooperation, 2005.

Dennis Maciuszek: Towards Dependable Virtual Companions for Later Life, 2005.

Beatrice Alenljung: Decision-making in the Requirements Engineering Process: A Human-centered Approach, 2005.

Anders Larsson: System-on-Chip Test Scheduling and Test Infrastructure Design, 2005.

John Wilander: Policy and Implementation Assurance for Software Security, 2005.

Andreas Käll: Översättningar av en managementmodell - En studie av införandet av Balanced Scorecard i ett landsting, 2005.

He Tan: Aligning and Merging Biomedical Ontologies, 2006.

Artur Wilk: Descriptive Types for XML Query Language Xcerpt, 2006.

Per Olof Pettersson: Sampling-based Path Planning for an Autonomous Helicopter, 2006.

Kalle Burbeck: Adaptive Real-time Anomaly Detection for Safeguarding Critical Networks, 2006.

Daniela Mihailescu: Implementation Methodology in Action: A Study of an Enterprise Systems Implementation Methodology, 2006.

Jörgen Skågeby: Public and Non-public gifting on the Internet, 2006.

Karolina Eliasson: The Use of Case-Based Reasoning in a Human-Robot Dialog System, 2006.

Misook Park-Westman: Managing Competence Development Programs in a Cross-Cultural Organisation - What are the Barriers and Enablers, 2006.

Amra Halilovic: Ett praktikperspektiv på hantering av mjukvarukomponenter, 2006.

Raquel Flodström: A Framework for the Strategic Management of Information Technology, 2006.

Viacheslav Izosimov: Scheduling and Optimization of Fault-Tolerant Embedded Systems, 2006.

Håkan Hasewinkel: A Blueprint for Using Commercial Games off the Shelf in Defence Training, Education and Research Simulations, 2006.

Hanna Broberg: Verksamhetsanpassade IT-stöd - Designteori och metod, 2006.

Robert Kaminski: Towards an XML Document Restructuring Framework, 2006.

Jiri Trnka: Prerequisites for data sharing in emergency management, 2007.

Björn Hägglund: A Framework for Designing Constraint Stores, 2007.

Daniel Andreasson: Slack-Time Aware Dynamic Routing Schemes for On-Chip Networks, 2007.

Magnus Ingmarsson: Modelling User Tasks and Intentions for Service Discovery in Ubiquitous Computing, 2007.

Gustaf Svedjemo: Ontology as Conceptual Schema when Modelling Historical Maps for Database Storage, 2007.

Gianpaolo Conte: Navigation Functionalities for an Autonomous UAV Helicopter, 2007.

Ola Leifler: User-Centric Critiquing in Command and Control: The DKExpert and ComPlan Approaches, 2007.

Henrik Svensson: Embodied simulation as off-line representation, 2007.

Zhiyuan He: System-on-Chip Test Scheduling with Defect-Probability and Temperature Considerations, 2007.

Jonas EImqvist: Components, Safety Interfaces and Compositional Analysis, 2007.

Håkan Sundblad: Question Classification in Question Answering Systems, 2007.

Magnus Lundqvist: Information Demand and Use: Improving Information Flow within Small-scale Business Contexts, 2007.

Martin Magnusson: Deductive Planning and Composite Actions in Temporal Action Logic, 2007.

Mikael Asplund: Restoring Consistency after Network Partitions, 2007.

Martin Fransson: Towards Individualized Drug Dosage - General Methods and Case Studies, 2007.

Karin Camara: A Visual Query Language Served by a Multi-sensor Environment, 2007.

David Broman: Safety, Security, and Semantic Aspects of Equation-Based Object-Oriented Languages and Environments, 2007.

Mikhail Chalabine: Invasive Interactive Parallelization, 2007.

Susanna Nilsson: A Holistic Approach to Usability Evaluations of Mixed Reality Systems, 2008.

Shanai Ardi: A Model and Implementation of a Security Plug-in for the Software Life Cycle, 2008.

Erik Kuiper: Mobility and Routing in a Delay-tolerant Network of Unmanned Aerial Vehicles, 2008.

Jana Rambusch: Situated Play, 2008.

Martin Karresand: Completing the Picture - Fragments and Back Again, 2008.

Per Nyblom: Dynamic Abstraction for Interleaved Task Planning and Execution, 2008.

Fredrik Lantz: Terrain Object Recognition and Context Fusion for Decision Support, 2008.

Martin Östlund: Assistance Plus: 3D-mediated Advice-giving on Pharmaceutical Products, 2008.

Håkan Lundvall: Automatic Parallelization using Pipelining for Equation-Based Simulation Languages, 2008.

Mirko Thorstensson: Using Observers for Model Based Data Collection in Distributed Tactical Operations, 2008.

Bahlol Rahimi: Implementation of Health Information Systems, 2008.

Maria Holmqvist: Word Alignment by Re-using Parallel Phrases, 2008.

Mattias Eriksson: Integrated Software Pipelining, 2009.

Annika Öhgren: Towards an Ontology Development Methodology for Small and Medium-sized Enterprises, 2009.

Rickard Holsmark: Deadlock Free Routing in Mesh Networks on Chip with Regions, 2009.

Sara Stymne: Compound Processing for Phrase-Based Statistical Machine Translation, 2009.

Tommy Ellqvist: Supporting Scientific Collaboration through Workflows and Provenance, 2009.

Fabian Segelström: Visualisations in Service Design, 2010.

Min Bao: System Level Techniques for Temperature-Aware Energy Optimization, 2010.

Mohammad Saifullah: Exploring Biologically Inspired Interactive Networks for Object Recognition, 2011 
No 1468 Qiang Liu: Dealing with Missing Mappings and Structure in a Network of Ontologies, 2011.

No 1469 Ruxandra Pop: Mapping Concurrent Applications to Multiprocessor Systems with Multithreaded Processors and Network on Chip-Based Interconnections, 2011.

No 1476 Per-Magnus Olsson: Positioning Algorithms for Surveillance Using Unmanned Aerial Vehicles, 2011.

No 1481 Anna Vapen: Contributions to Web Authentication for Untrusted Computers, 2011.

No 1485 Loove Broms: Sustainable Interactions: Studies in the Design of Energy Awareness Artefacts, 2011.

FiF-a 101 Johan Blomkvist: Conceptualising Prototypes in Service Design, 2011.

No 1490 Håkan Warnquist: Computer-Assisted Troubleshooting for Efficient Off-board Diagnosis, 2011.

No 1503 Jakob Rosén: Predictable Real-Time Applications on Multiprocessor Systems-on-Chip, 2011.

No 1504 Usman Dastgeer: Skeleton Programming for Heterogeneous GPU-based Systems, 2011.

No 1506 David Landén: Complex Task Allocation for Delegation: From Theory to Practice, 2011.

No 1507 Kristian Stavåker: Contributions to Parallel Simulation of Equation-Based Models on

Graphics Processing Units, 2011.

No 1509 Mariusz Wzorek: Selected Aspects of Navigation and Path Planning in Unmanned Aircraft Systems, 2011.

No 1510 Piotr Rudol: Increasing Autonomy of Unmanned Aircraft Systems Through the Use of Imaging Sensors, 2011.

No 1513 Anders Carstensen: The Evolution of the Connector View Concept: Enterprise Models for Interoperability Solutions in the Extended Enterprise, 2011.

https://www.ida.liu.se/local/mrbs/view entry.php?room=297\&area=70\&id=260881\&day=13\&month=3\&year=2014No

Jody Foo: Computational Terminology: Exploring Bilingual and Monolingual Term Extraction, 2012.

No 1550 Anders Fröberg: Models and Tools for Distributed User Interface Development, 2012.

No 1558 Dimitar Nikolov: Optimizing Fault Tolerance for Real-Time Systems, 2012.

No 1582 Dennis Andersson: Mission Experience: How to Model and Capture it to Enable Vicarious Learning, 2013.

No 1586 Massimiliano Raciti: Anomaly Detection and its Adaptation: Studies on Cyber-physical Systems, 2013.

No 1588 Banafsheh Khademhosseinieh: Towards an Approach for Efficiency Evaluation of Enterprise Modeling Methods, 2013.

No 1589 Amy Rankin: Resilience in High Risk Work: Analysing Adaptive Performance, 2013.

No 1592 Martin Sjölund: Tools for Understanding, Debugging, and Simulation Performance Improvement of EquationBased Models, 2013.

No 1606 Karl Hammar: Towards an Ontology Design Pattern Quality Model, 2013.

No 1624 Maria Vasilevskaya: Designing Security-enhanced Embedded Systems: Bridging Two Islands of Expertise, 2013.

No 1627 Ekhiotz Vergara: Exploiting Energy Awareness in Mobile Communication, 2013.

No 1644 Valentina Ivanova: Integration of Ontology Alignment and Ontology Debugging for Taxonomy Networks, 2014.

No 1647 Dag Sonntag: A Study of Chain Graph Interpretations, 2014.

No 1657 Kiril Kiryazov: Grounding Emotion Appraisal in Autonomous Humanoids, 2014. 